\title{
Ferroelectric HfZrO Films: Process, Characterization and Devices
}

R.D. Clark, ${ }^{1}$ K. Tapily, ${ }^{1}$ S. Consiglio, ${ }^{1}$ C.S. Wajda, ${ }^{1}$ K. Ni, ${ }^{3}$ S. Dey, ${ }^{2}$ Vineetha Mukundan, ${ }^{2}$ K. Beckman, ${ }^{2}$ G.J. Leusink, ${ }^{1}$ N. Cady, ${ }^{2}$ A.C. Diebold, ${ }^{2}$ and S. Datta ${ }^{3}$

${ }^{1}$ TEL Technology Center, America, LLC., Albany, NY 12203, USA ${ }^{2}$ Colleges of Nanoscale Science and Engineering, SUNY Polytechnic Institute, 257 Fuller Rd., Albany, NY 12203, USA. ${ }^{3}$ Department of Electrical Engineering, University of Notre Dame, Notre Dame, IN, 46556, USA.

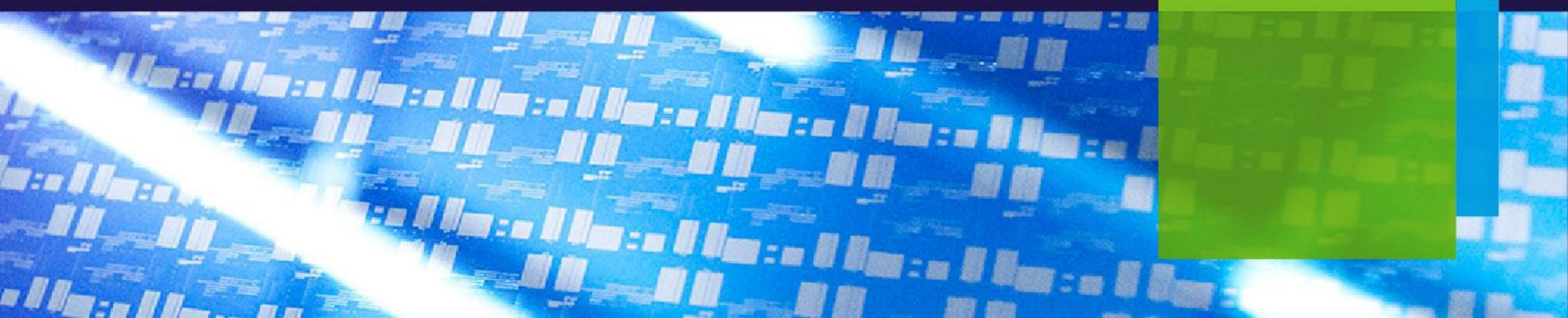




\section{Outline}

- Introduction

- Ferroelectric $\mathrm{HfZrO}$

- Motivation and Methodology of Film Formation

- Physical and Electrical Characteristics

- Applications

- Memories

- Digital Logic Devices

- Neuromorphic Devices

- Summary and Conclusions 


\section{Ferroelectric Films}

- Two distinct polarization states (remnant polarization)

- Maintained in the absence of an electric field

- Can be switched by an electric field
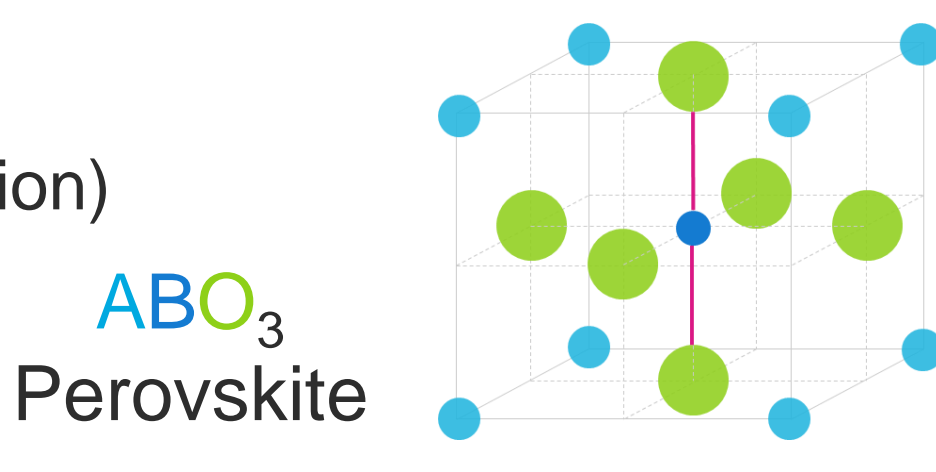

Centrosymmetric

Electric field applied

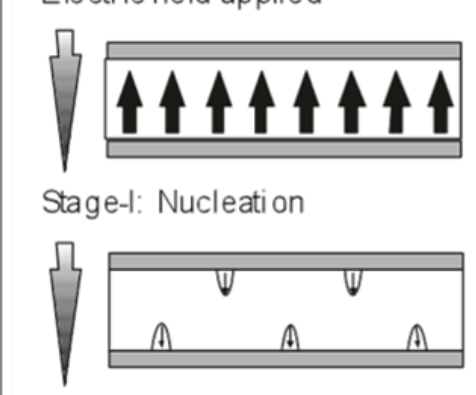

Stage-II: Forward Growth

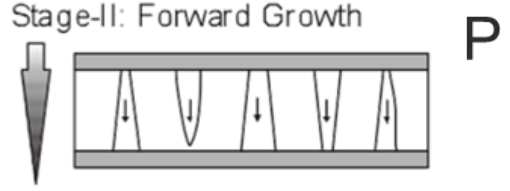

tag e-III : Sid eways G rowth

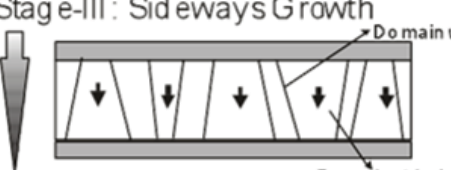

Domain reversal complete

\section{in+1+th}
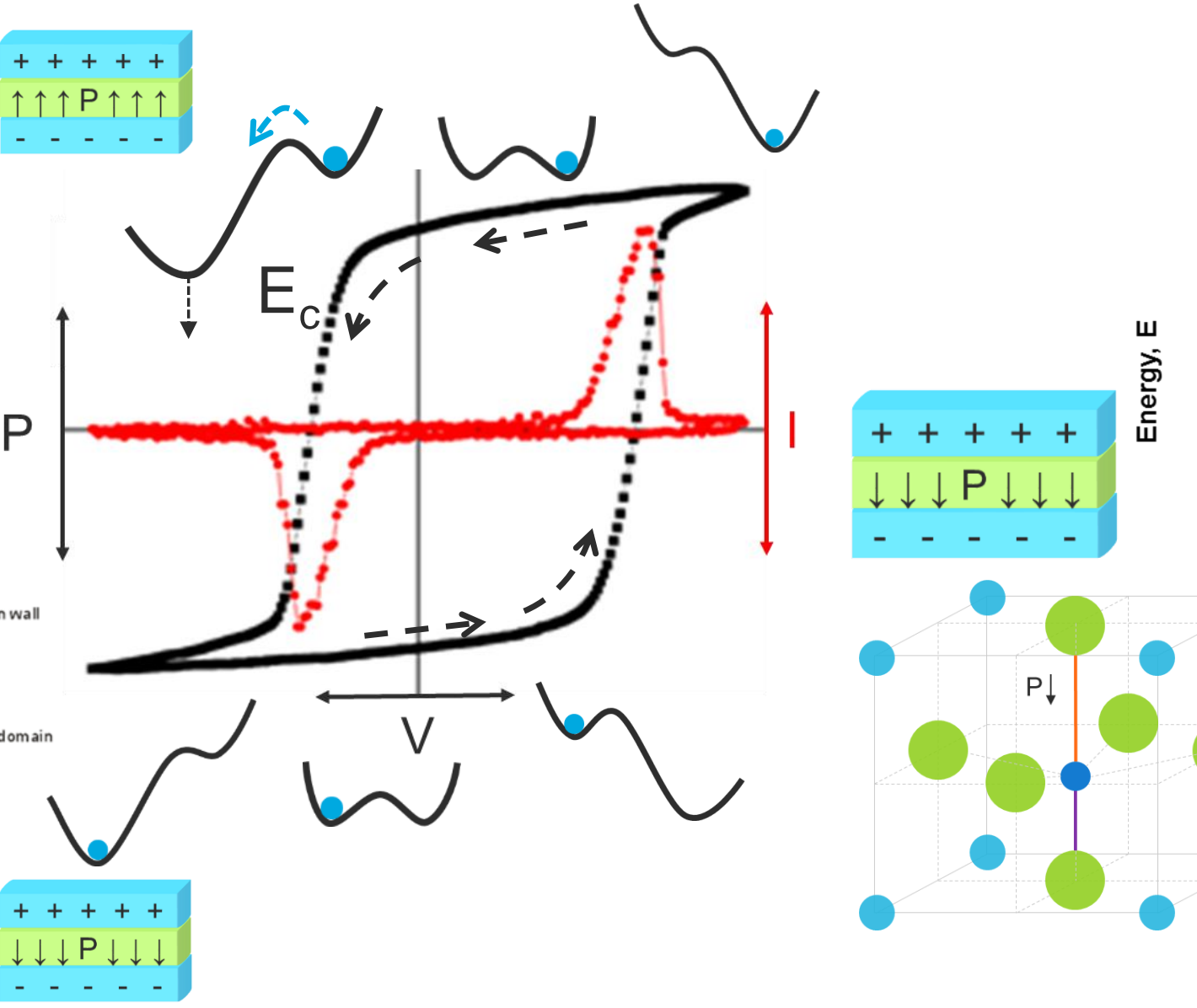

O

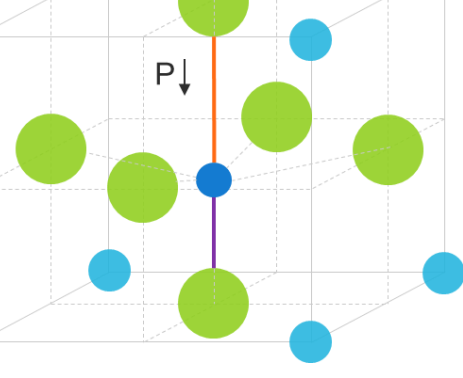

Non-Centrosymmetric

Ferroelectric

$\mathrm{T}<\mathrm{T}_{\mathrm{C}}$ $\uparrow \uparrow \uparrow \uparrow \uparrow$
++++

0

0

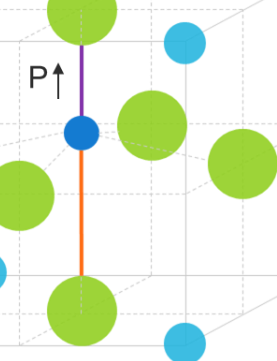




\section{Ferroelectricity in Hafnium Oxide based Thin Films}

\section{- Engineered $\mathrm{HfO}_{2}$}

- Anneal, etc.

See: Muller et. al. APL 99, 112901 (2011)

- Doped $\mathrm{HfO}_{2}$ Boscke et. al. APL 99, 102903 (2011)

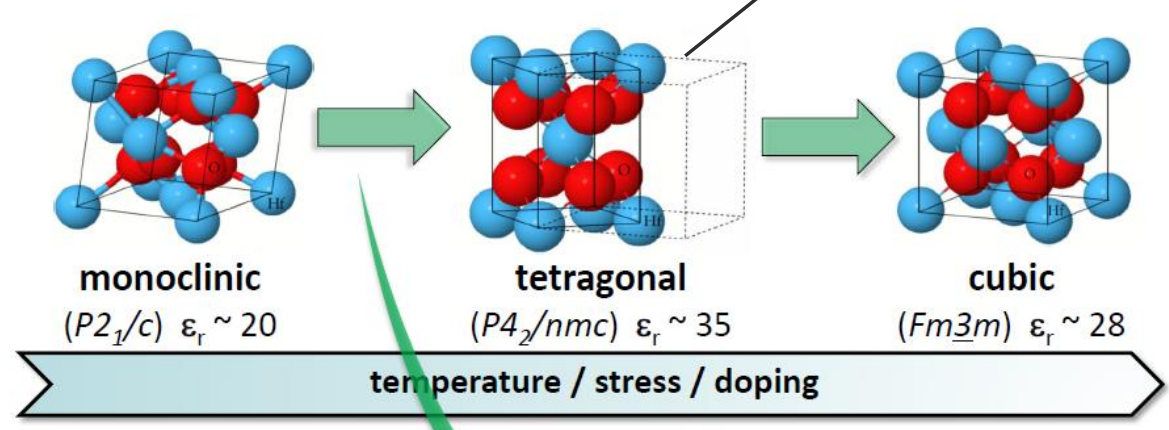

- Zr, Al, Gd, La, Si, Sr and Y

- Ferroelectricity in $\mathrm{HfO}_{2}$ origin is attributed to the non centrosymmetric orthorhombic phase

- Currently Ferroelectric films are considered for Ferroelectric RAM (FeRAM), Ferroelectric FETs and as gate dielectrics for negative capacitance FETs (NCFETs)

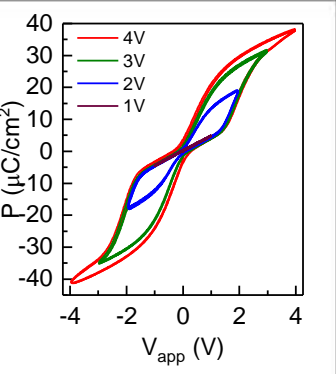

intermediate orthorhombic phase

$\left(P b c 2_{1}\right) \varepsilon_{\mathrm{r}} \sim 25$
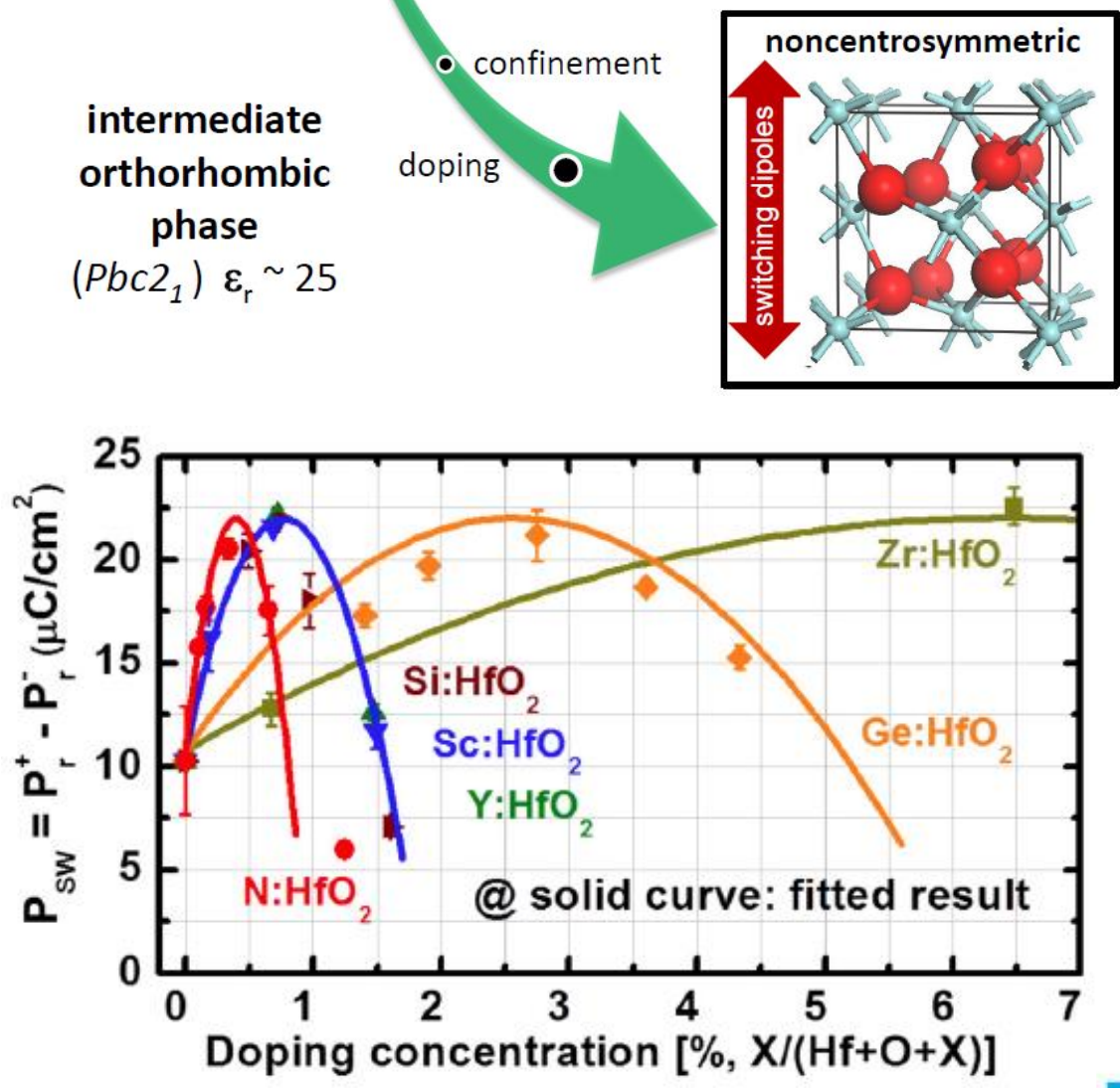

Xu et. al. JAP 122, 124104 (2017) 


\section{Forming Ferroelectric HfZrO}

$5 \mathrm{~nm} \mathrm{TiN} / 7 \mathrm{~nm} \mathrm{Hf} \mathrm{Hi}_{0.2} \mathrm{Zr}_{0.8} \mathrm{O}_{2} / \mathrm{Si}+700^{\circ} \mathrm{C} 30 \mathrm{sec}$. PMA

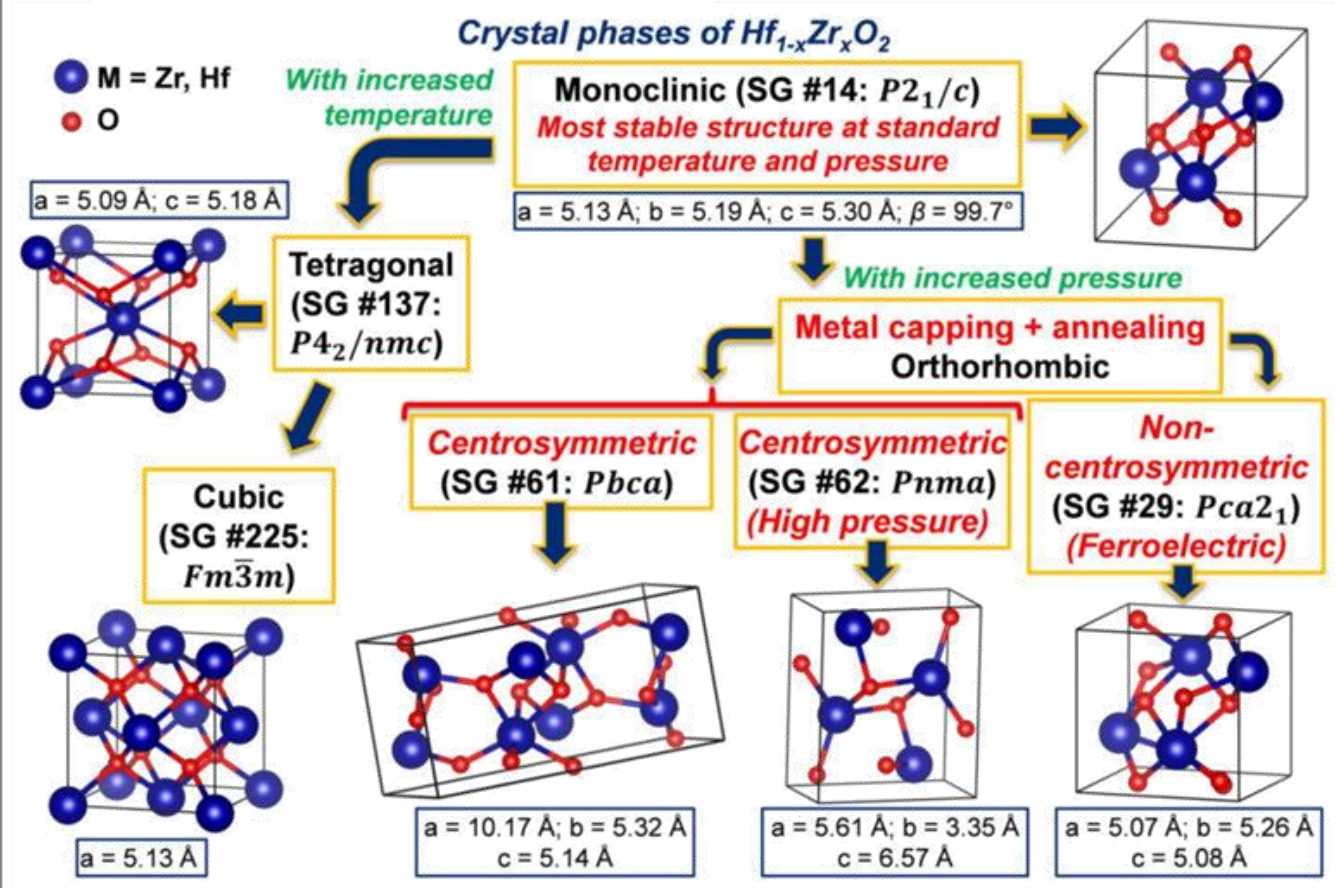

Adapted From: Dey et. al. FCMN 2017 Also: Sharma et. al. VLSI 2017

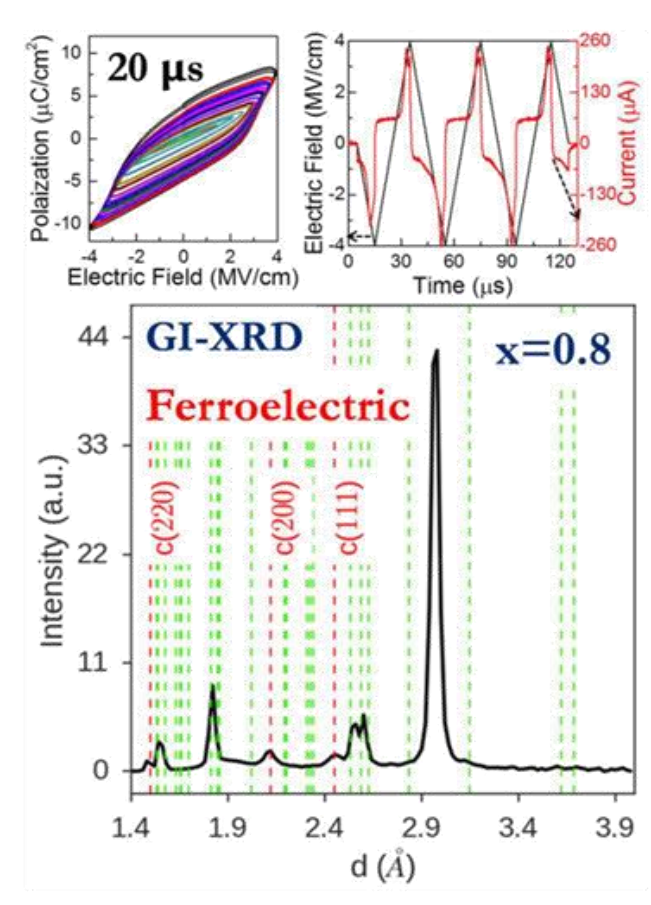

(4)
$\underline{X-a x e s}$ are defined as $\mathrm{x} /(\mathrm{x}+\mathrm{y})$ for:

Cycle Ratio: [(TEMAH/Ox $\left.)_{x}+(\text { TEMAZ/Ox })_{y}\right] x$ n cycles Molar Flow: [(x TEMAH + y TEMAZ)/Ox] x n cycles

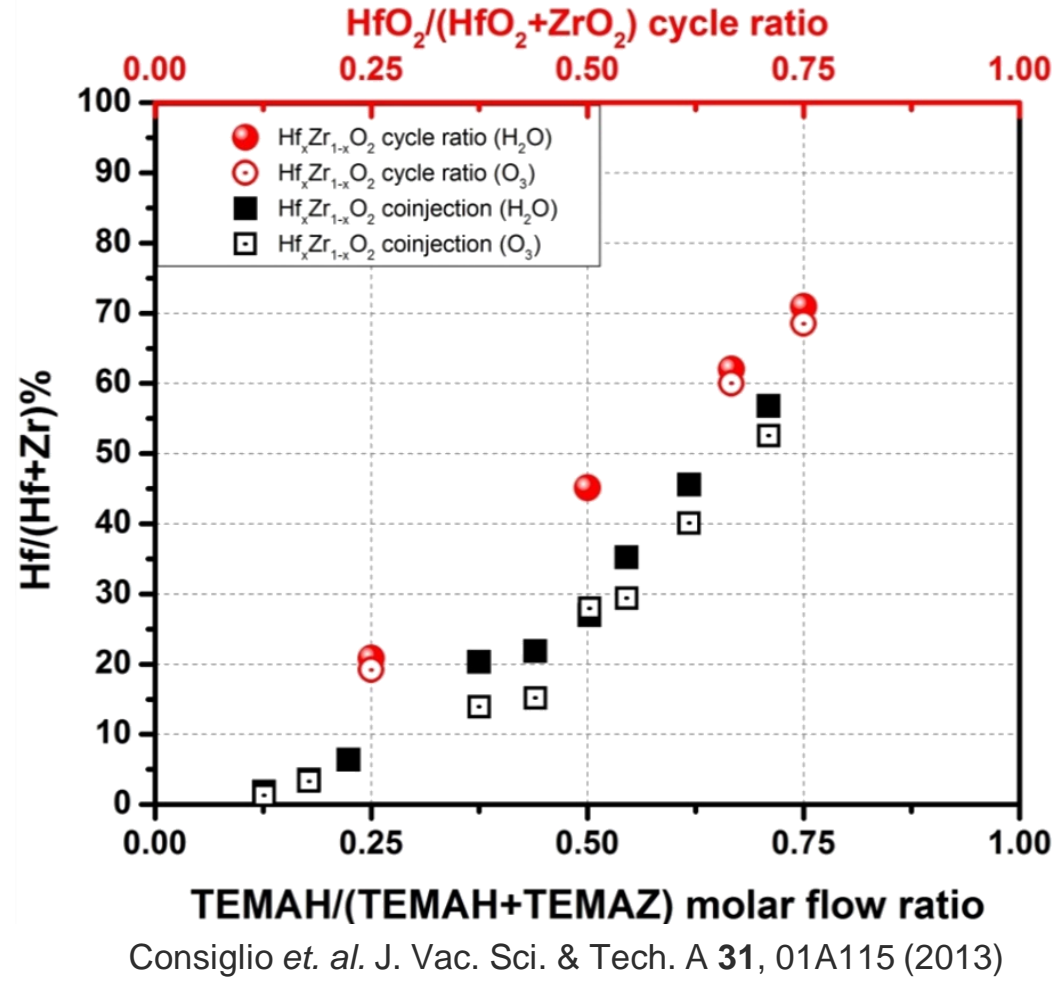

- To form the non-centrosymmetric orthorhombic phase thought to cause ferroelectric behavior specific process sequences are needed depending on the substrate.

- We have observed a strong correlation with peaks attributable to the tetragonal phase, which is anti-ferroelectric and a possible transition state in polarity flips. 


\section{Some Ferroelectric Device Possibilities}

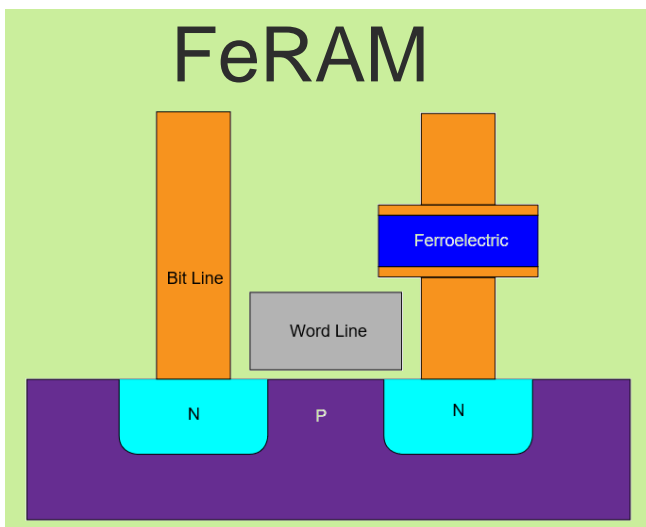

https://commons. wikimedia.org/w/ind ex.php?curid $=10542039$

Krivokapic, Z. IEDM 2017

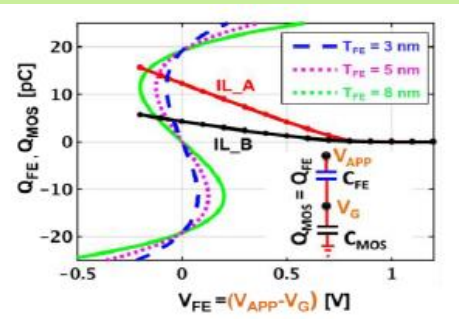

Fig. 4: Capacitance matching between $\mathrm{FE}$ capacitors and MOS positive $C_{F E}$, while for II $\_$B it occurs for negative $C_{F F}$.

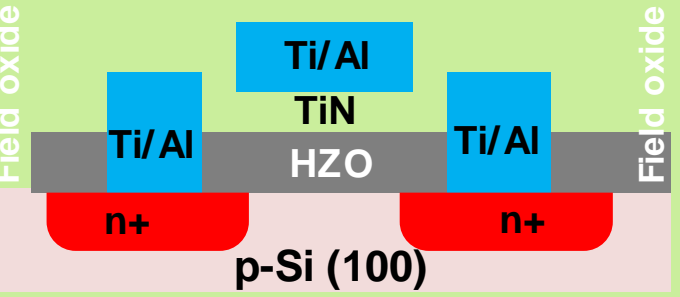

Sharma et. al. VLSI 2017

After positive gate pulse (polarization down)

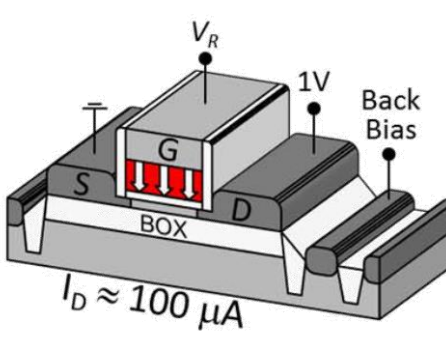

Low- $V_{T}$ state (polarization up)

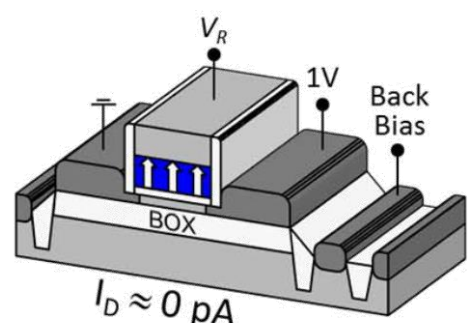

High- $V_{T}$ state
After negative gate pulse
Dunkel, S. IEDM 2017

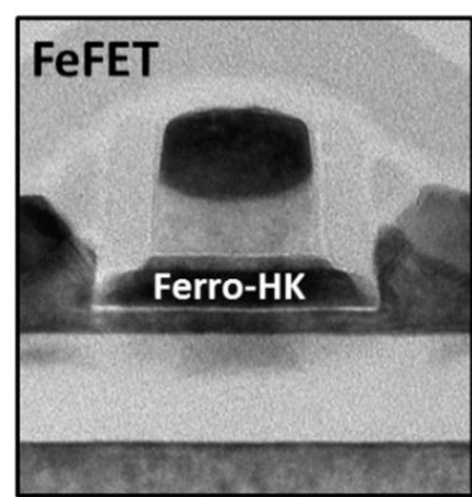

Florent, K. VLSI 2017 ig. 6: Variation of SS in the subthreshold regim for various transistor areas.

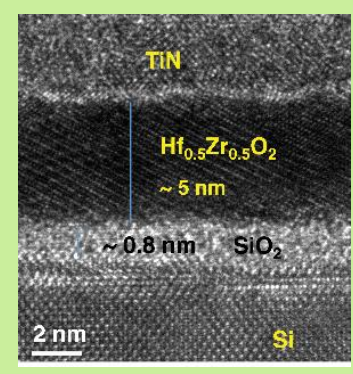

$\log I_{D}$ Low- $V_{T}$ state

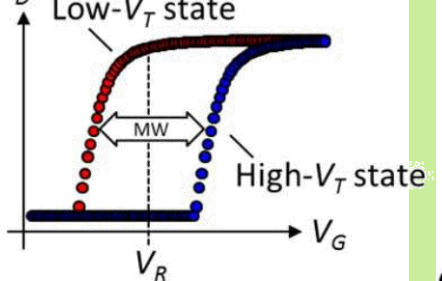

C

C

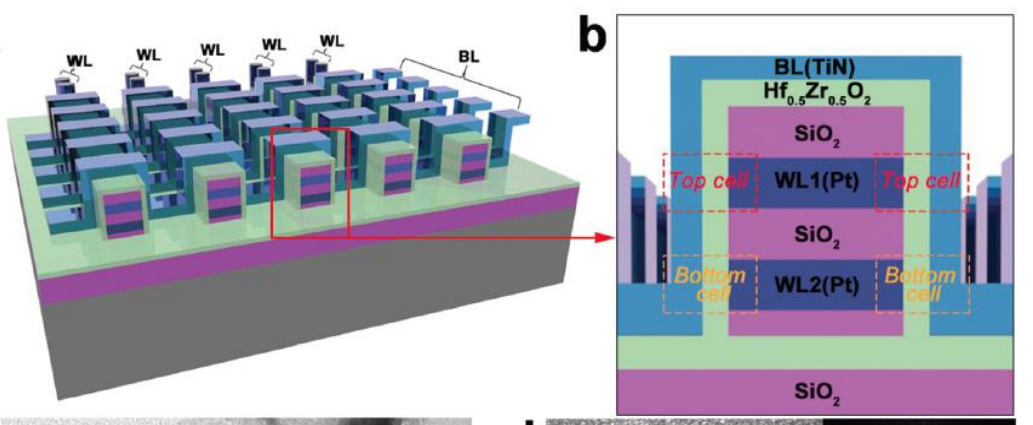

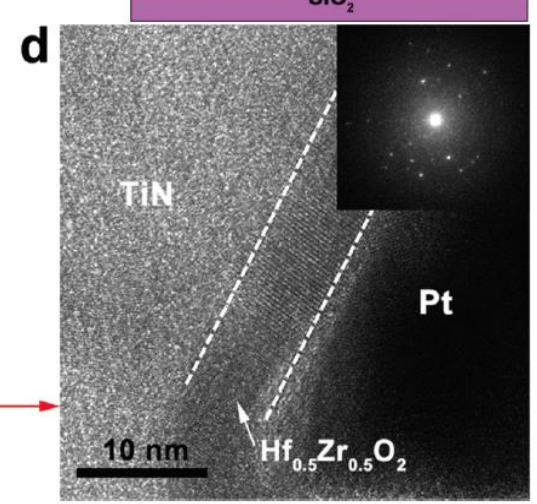

Chen, L. Nanoscale 2018, 10.1039/c8nr0473k

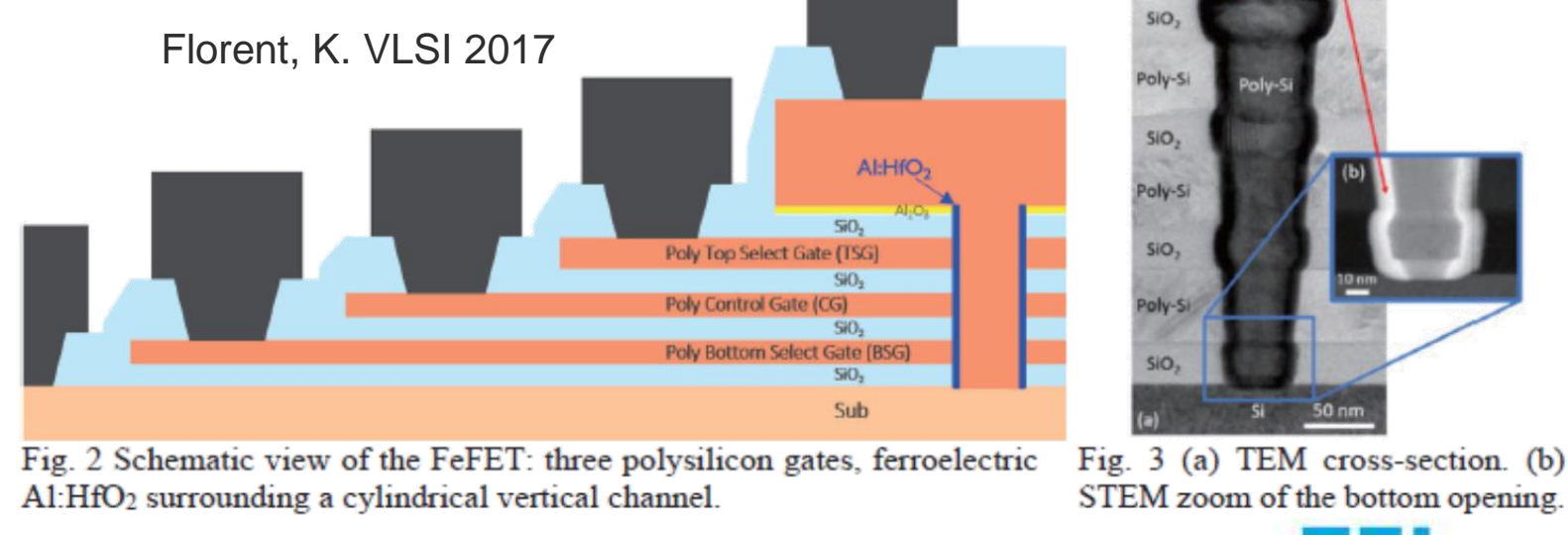

Fig. 2 Schematic view of the FeFET: three polysilicon gates, ferroelectric $\mathrm{Al}: \mathrm{HfO}_{2}$ surrounding a cylindrical vertical channel.

R. Clark / TTCA TFPT / ECS/Aimes 2018 October 1, 2018

TEL. 


\section{GI-XRD: (Apparently)Tetragonal correlates to polarization}

(PMA; 5nm) TiN/ (CR; 7nm) $\mathrm{Hf}_{1-\mathrm{x}} \mathrm{Zr}_{\mathrm{x}} \mathrm{O}_{2} / \mathrm{Si}$
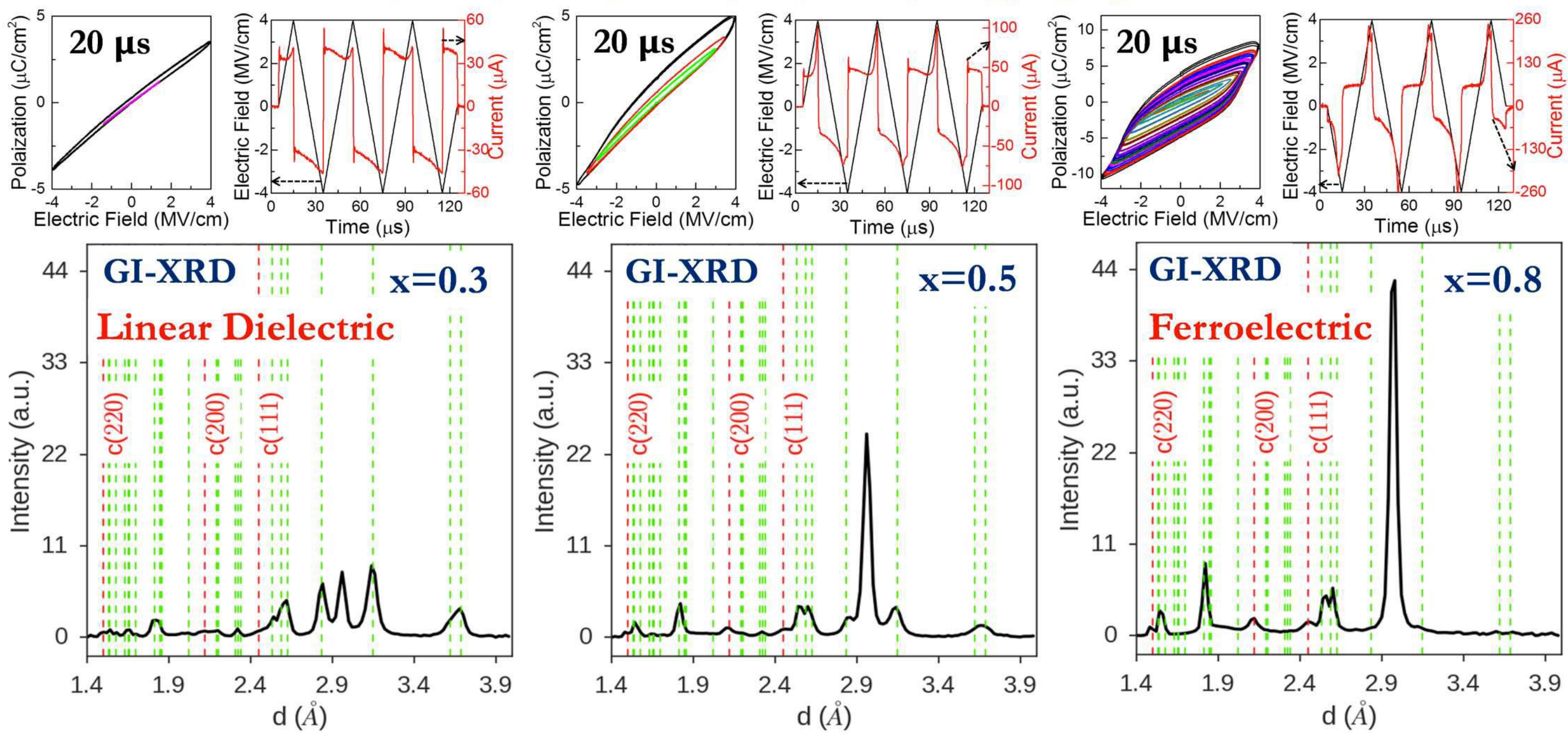


\section{7nm Films in MIM Structure - Varying Composition}
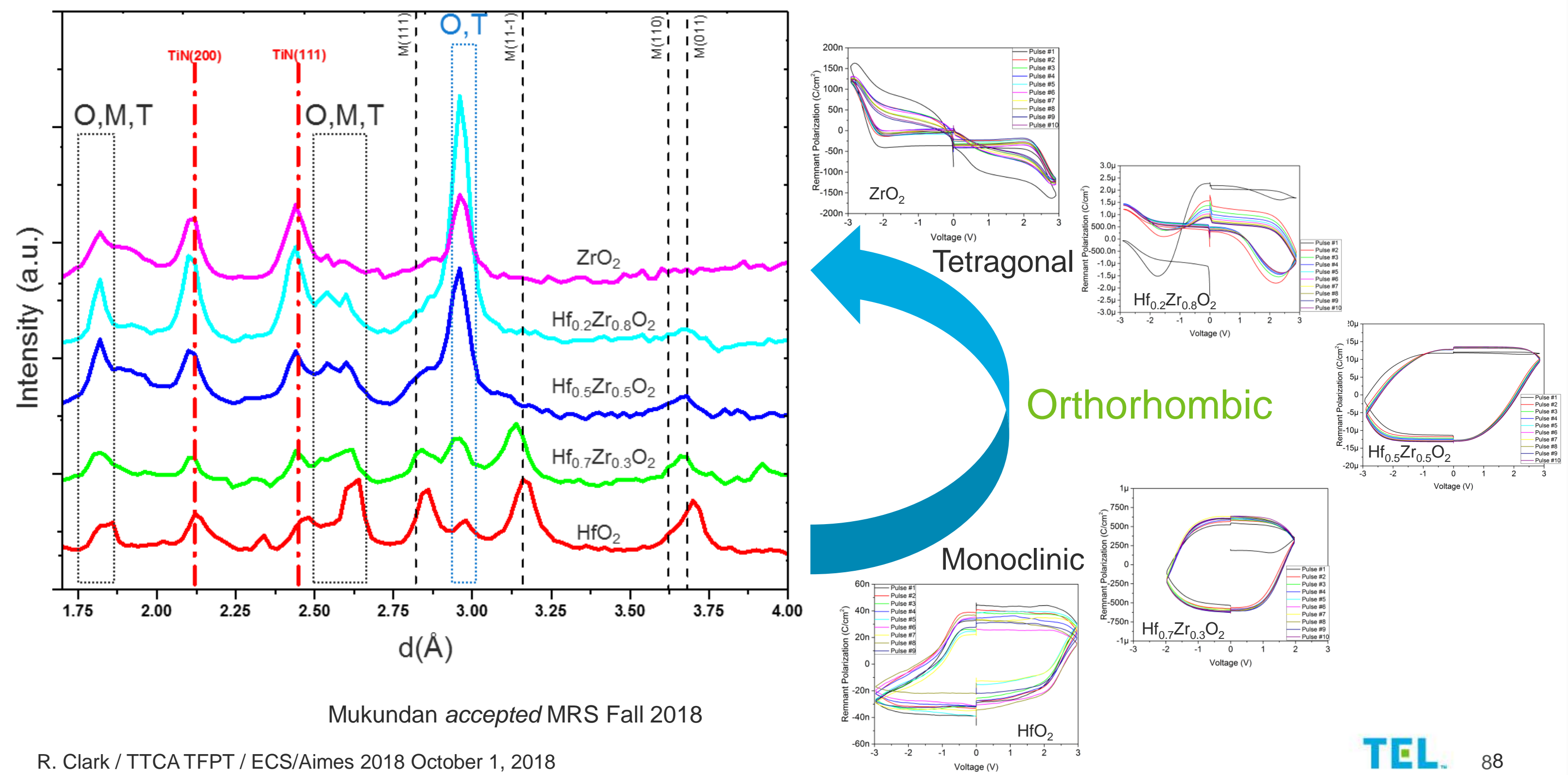

Mukundan accepted MRS Fall 2018 


\section{$7 \mathrm{~nm} \mathrm{Hf}_{0.5} \mathrm{Zr}_{0.5} \mathrm{O}_{2}$}

\section{MFM Devices}
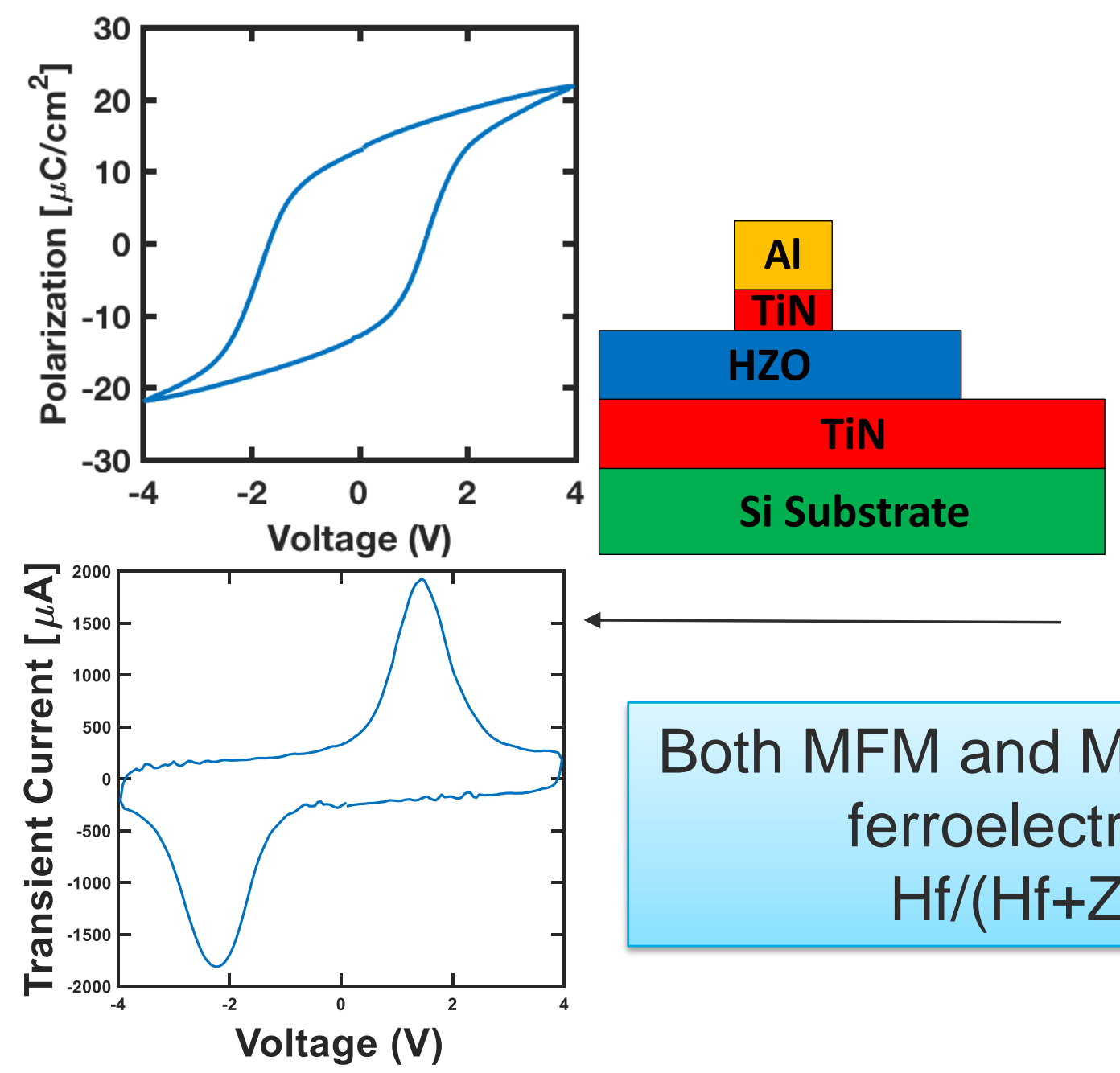

\section{Both MFM and MFIS shows similar} ferroelectric behavior $\mathrm{Hf} /(\mathrm{Hf}+\mathrm{Zr}) \%=50 \%$

\section{MFIS Devices}

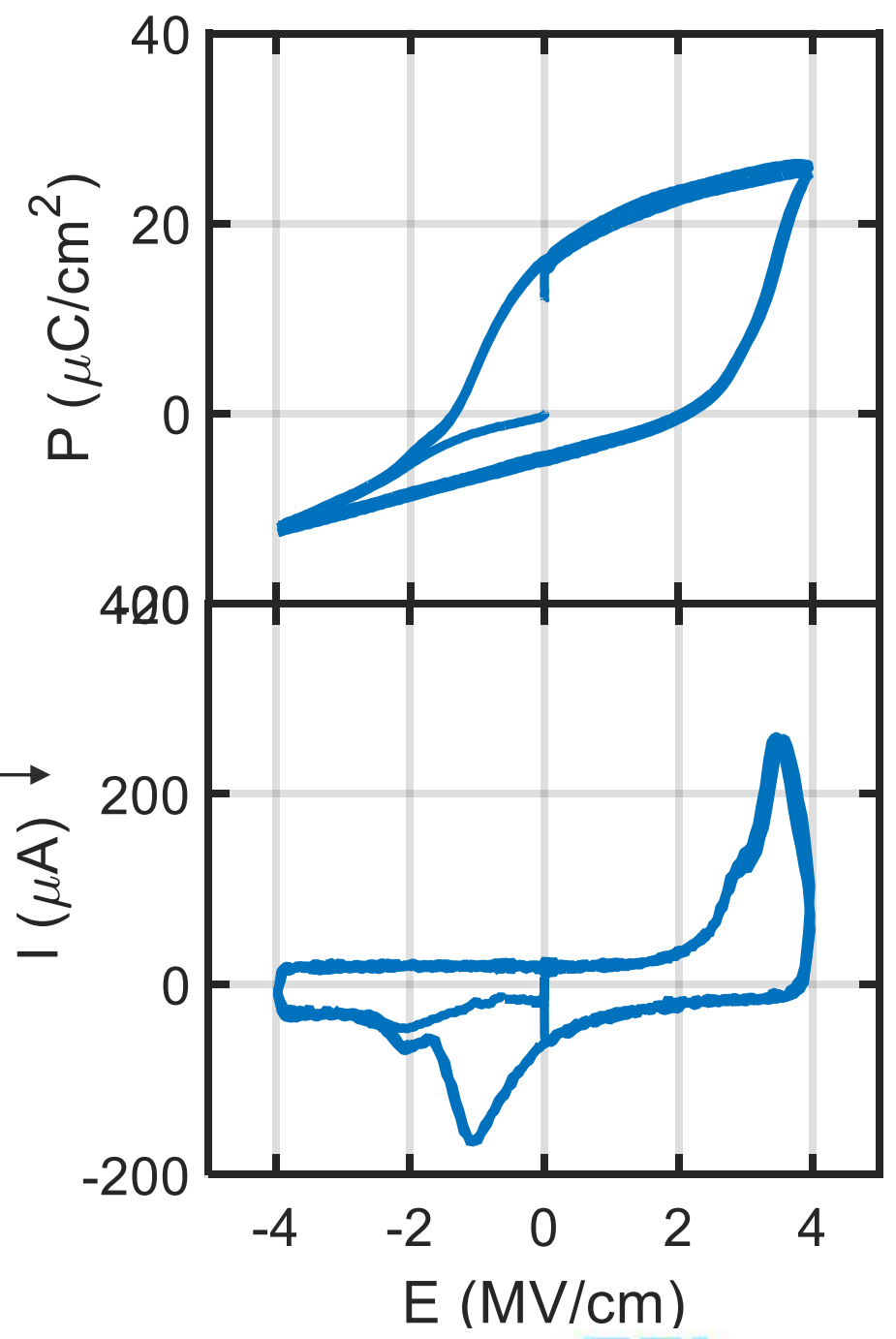

TEL. 10 


\section{MFM Devices}

\section{MFIS Devices}

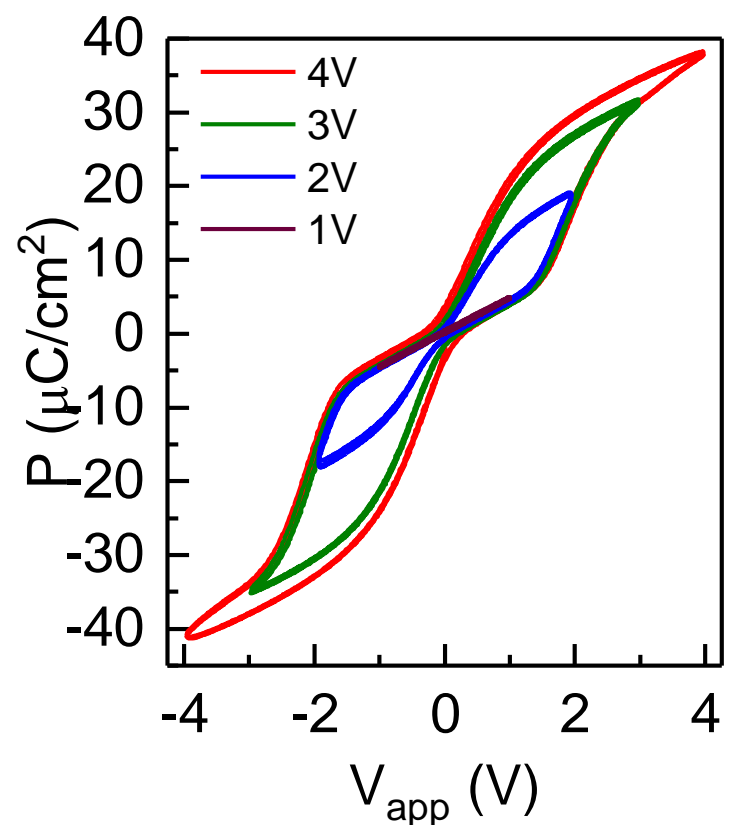

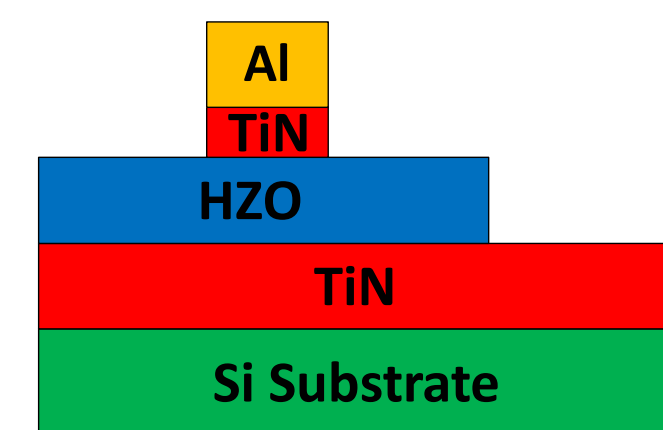

\section{MFM Devices show Anti-Ferroelectric} behavior, indicating Tetragonal $\mathrm{HfZrO}$; MFIS remains Ferroelectric

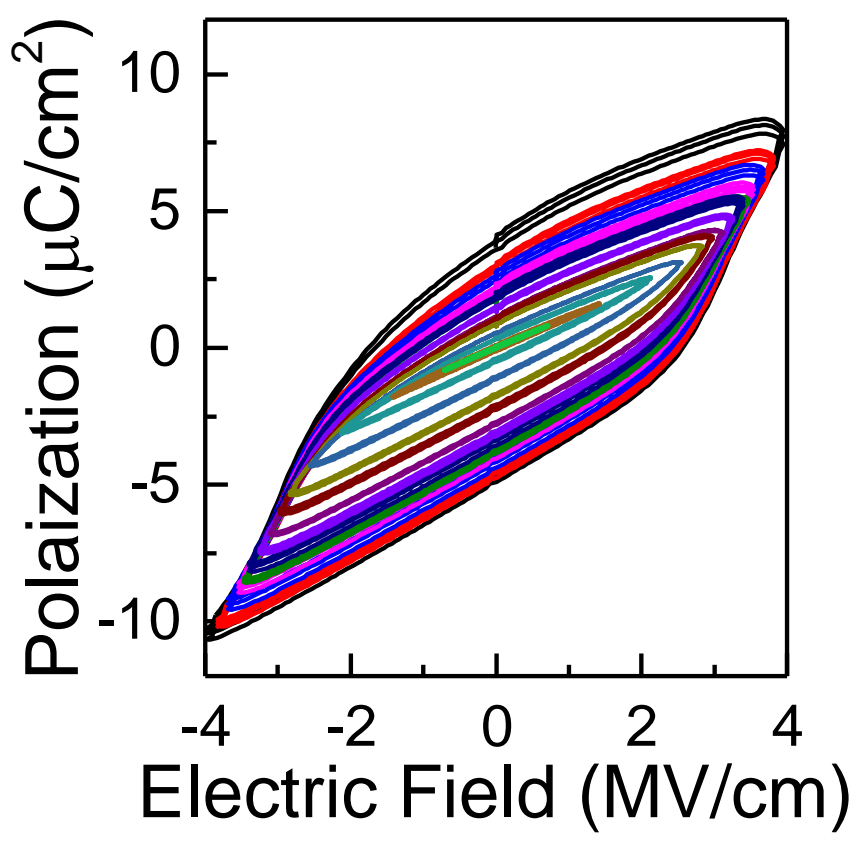

The observation of antiferroelectric behavior for Thin, High $\mathrm{Zr}$ films has been shown previously in the literature.

See: Park et. al. Nanoscale (2017) 10.1039/C7NR02121F 


\section{Ferroelectric FETs for Memory applications}
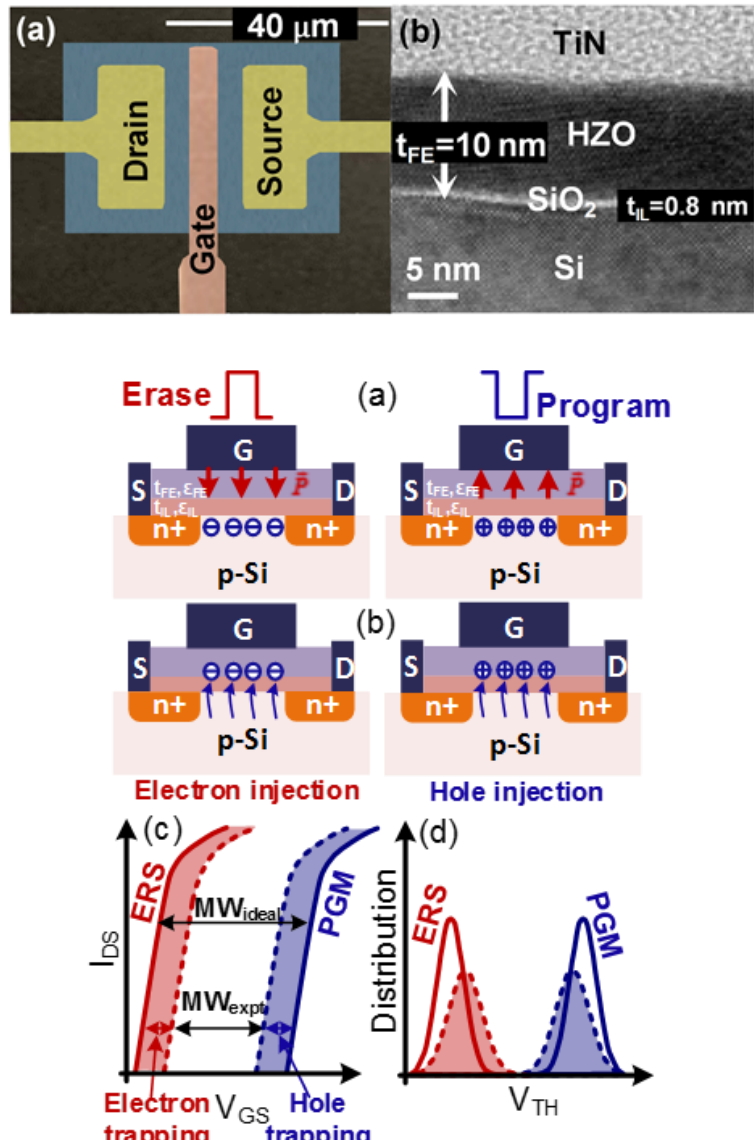

(a) Ferroelectric FETNVM operation; (b) Electron/hole trapping within gate stack during erase/program pulse, respectively; (c) Charge trapping narrows MW; (d) $V_{T H}$

distribution without (solid line), and with (dashed line) charge trapping. Charge trapping broadens and shifts distribution.

(b)

Energy band diagram during (a) erase and (b) program pulse.

Corresponding polarization is shown in green arrow. Charge trapping is

(a)

(a)
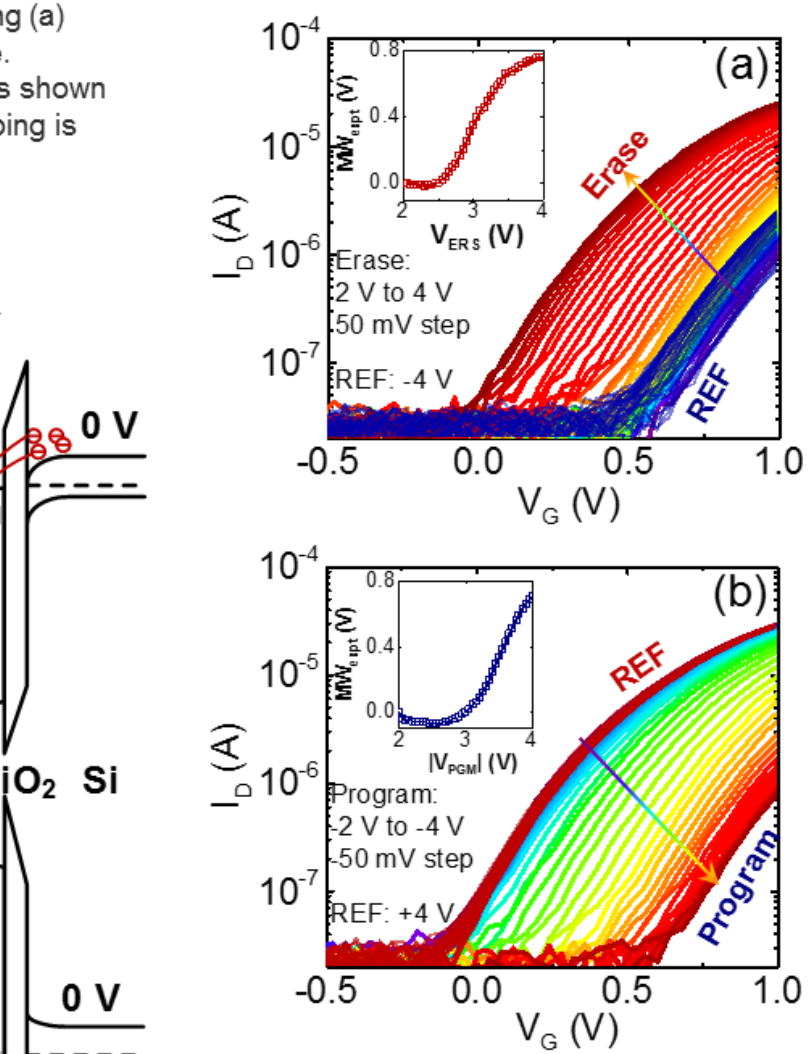

$I_{D}-V_{G}$ characteristics with increasing (a) erase and (b) program voltage amplitude. The inset shows the MW $\mathrm{W}_{\text {ext }}$ as a function of the write amplitude. MW

monotonically increases with amplitude. Pulse width of $500 \mathrm{~ns}$ is applied.
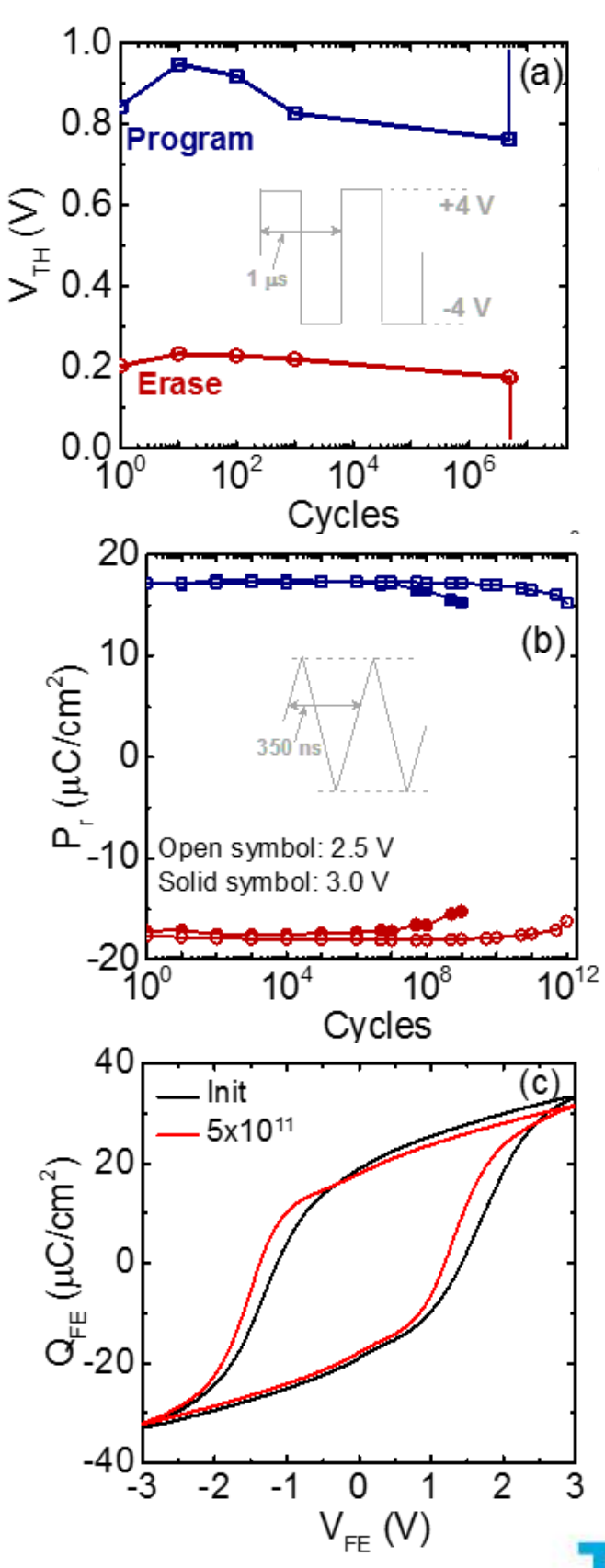

R. Clark / TTCA TFPT / ECS/Aimes 2018 October 1, 2018

Ni et. al. IEEE TED (2018) 65, 6, pp. 2461-9 


\section{Preventing Breakdown of IL and Optimizing MW}
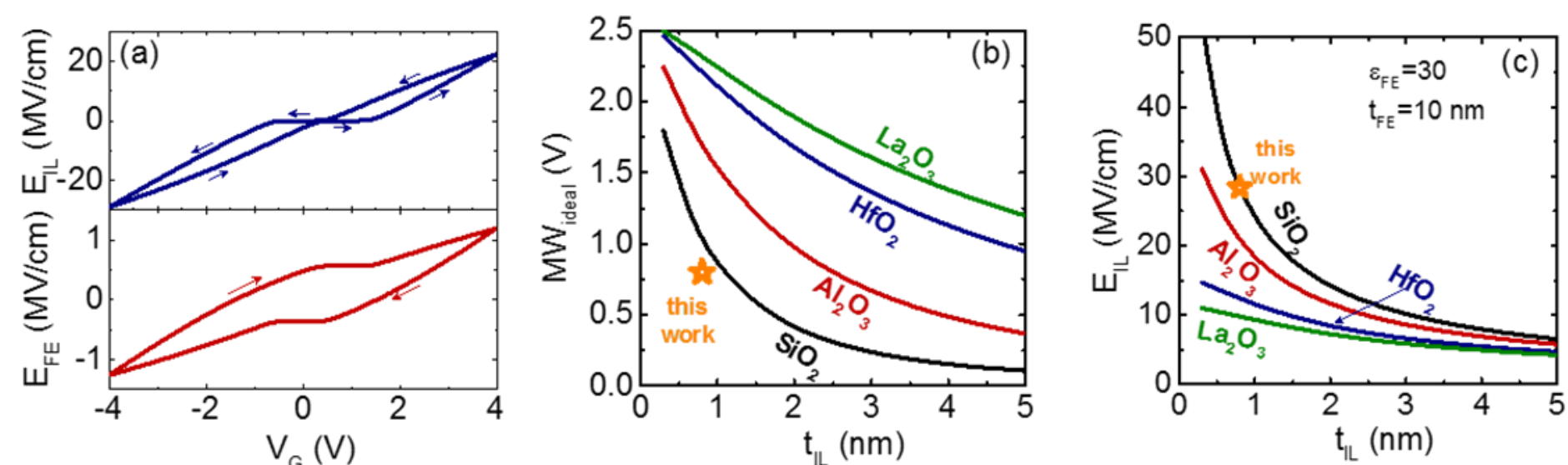

(a) Electric field distribution for $1 \mathrm{~nm} \mathrm{FE} / 0.8 \mathrm{~nm} \mathrm{SiO} \mathrm{IL}_{2}$ stack, $E_{/ L}>25 \mathrm{MV} / \mathrm{cm}$ (degrades reliability), while $E_{F E} \sim 1 \mathrm{MV} / \mathrm{cm}$ (reduces MW). (b) Simulated MW and (c) maximum $E_{/ L}$ as a function of IL composition/thickness.

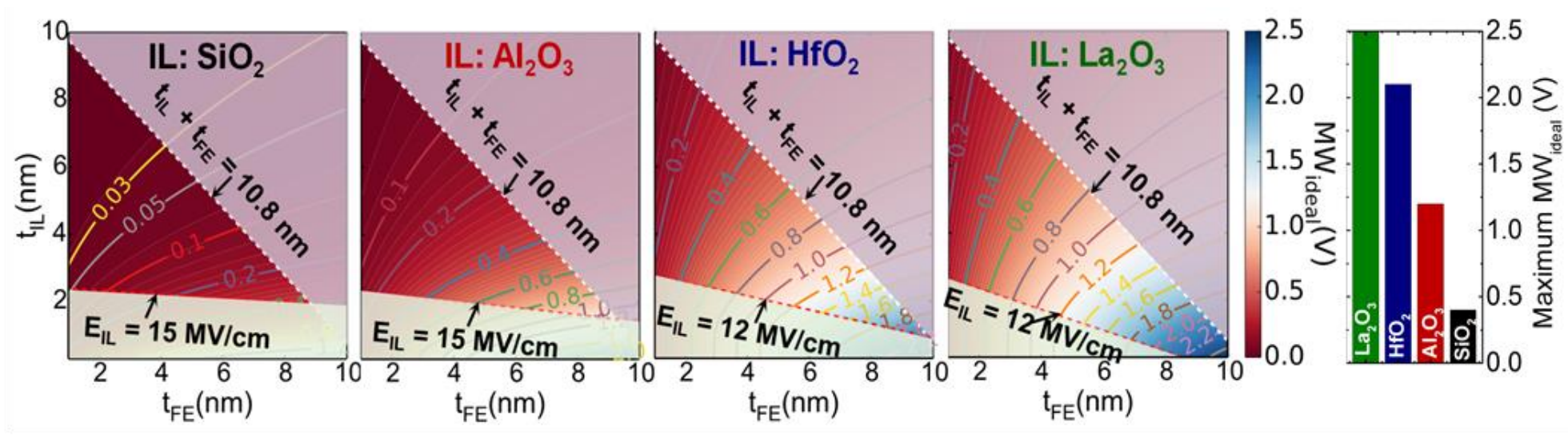

- High K interface layers are proposed as a countermeasure

(a) Design space exploration for four different interlayer dielectrics, bounded by constraints: (1) $t_{l l}+t_{F E} \leq 10.8 \mathrm{~nm}$, (2) $E_{\| \leq} \leq$ $12 \mathrm{MV} / \mathrm{cm}$ for $\mathrm{La}_{2} \mathrm{O}_{3}$ and $\mathrm{HfO}_{2}$ and $E_{1} \leq 15 \mathrm{MV} / \mathrm{cm}$ for $\mathrm{Al}_{2} \mathrm{O}_{3}$ and $\mathrm{SiO}_{2}$. (b) Maximum memory window satisfying all the constraints for four different interlayer dielectrics. $\varepsilon_{F E}$ kept at 30 is used for all thicknesses of $\mathrm{HZO}$. 


\section{Enhancement of Ferroelectricity Properties Via additional capping}
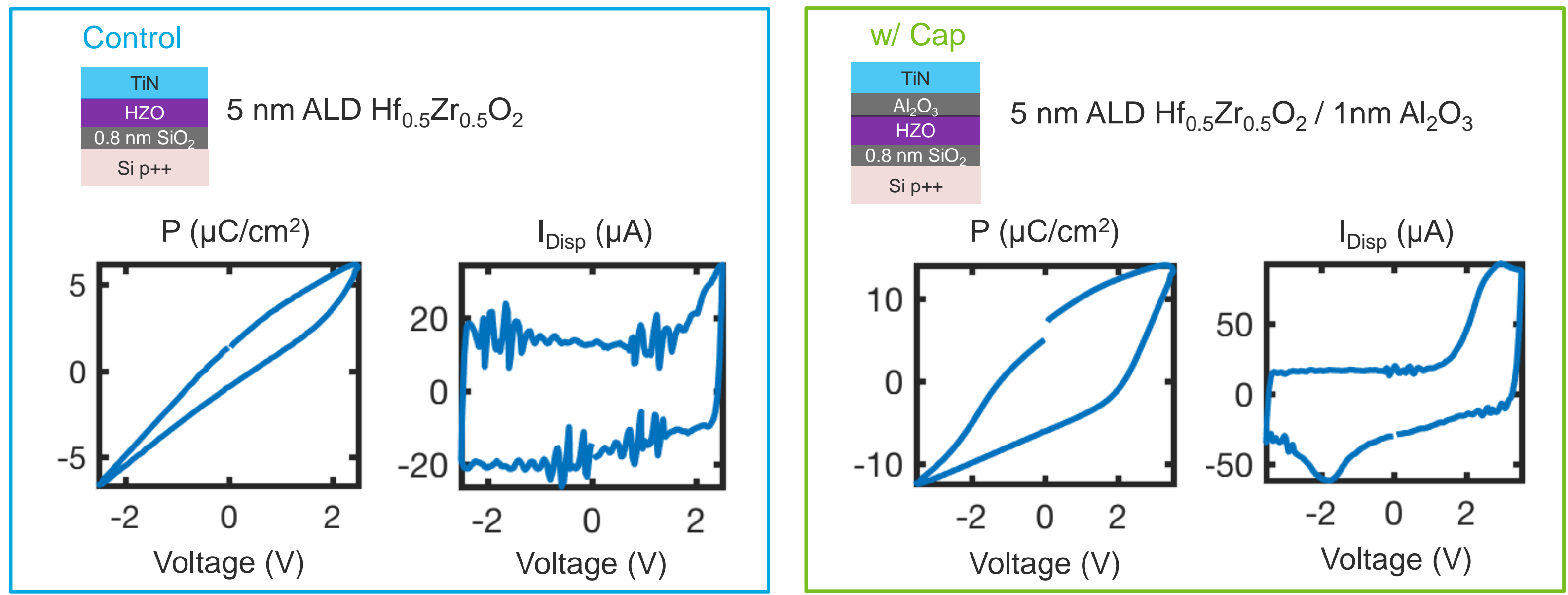

- Ferroelectricity enhanced by in situ cap

- Ideal for memory application 


\section{Switching Dynamic}

- Insertion of $\mathrm{Al}_{2} \mathrm{O}_{3}$ increases MW significantly
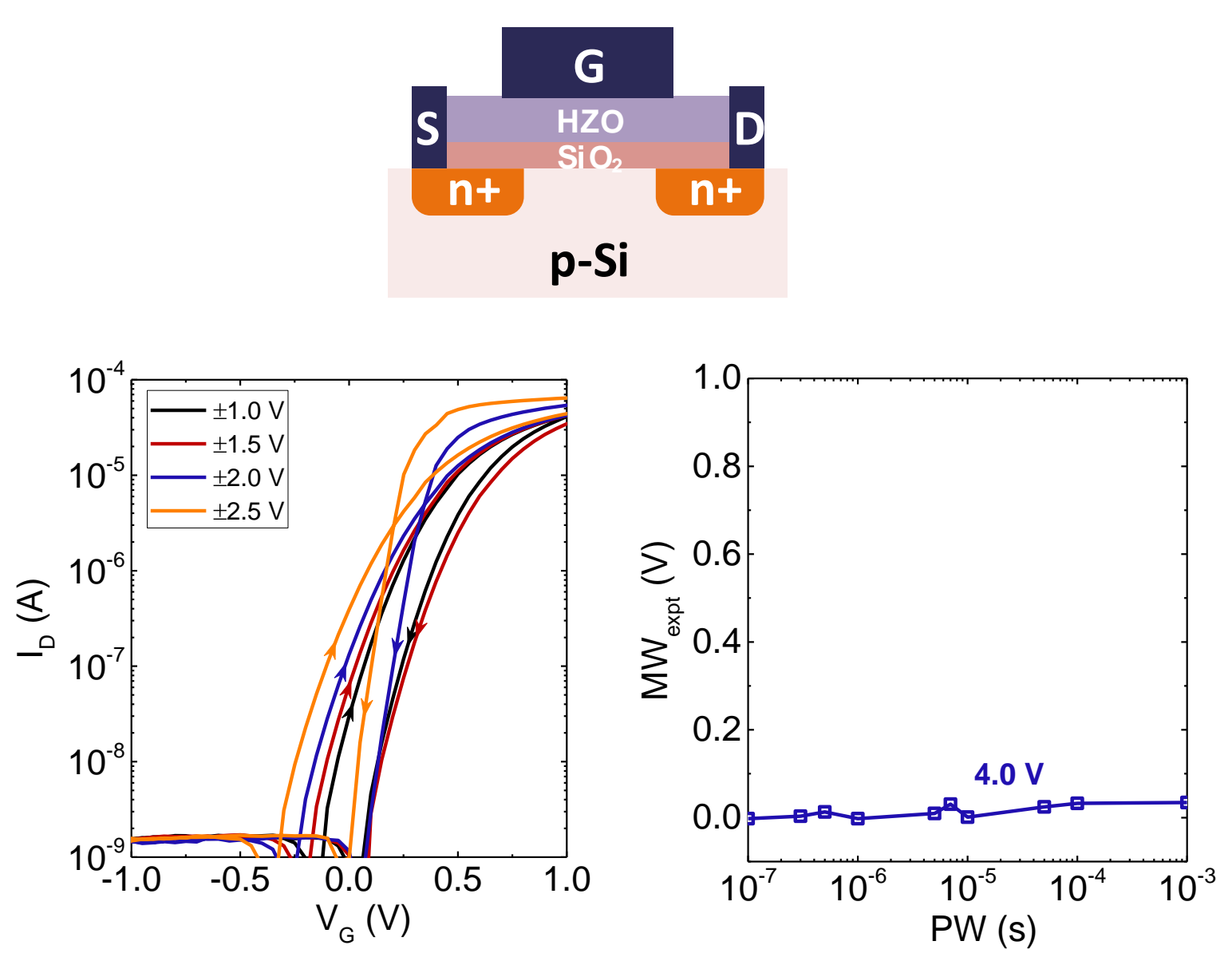

R. Clark / TTCA TFPT / ECS/Aimes 2018 October 1, 2018

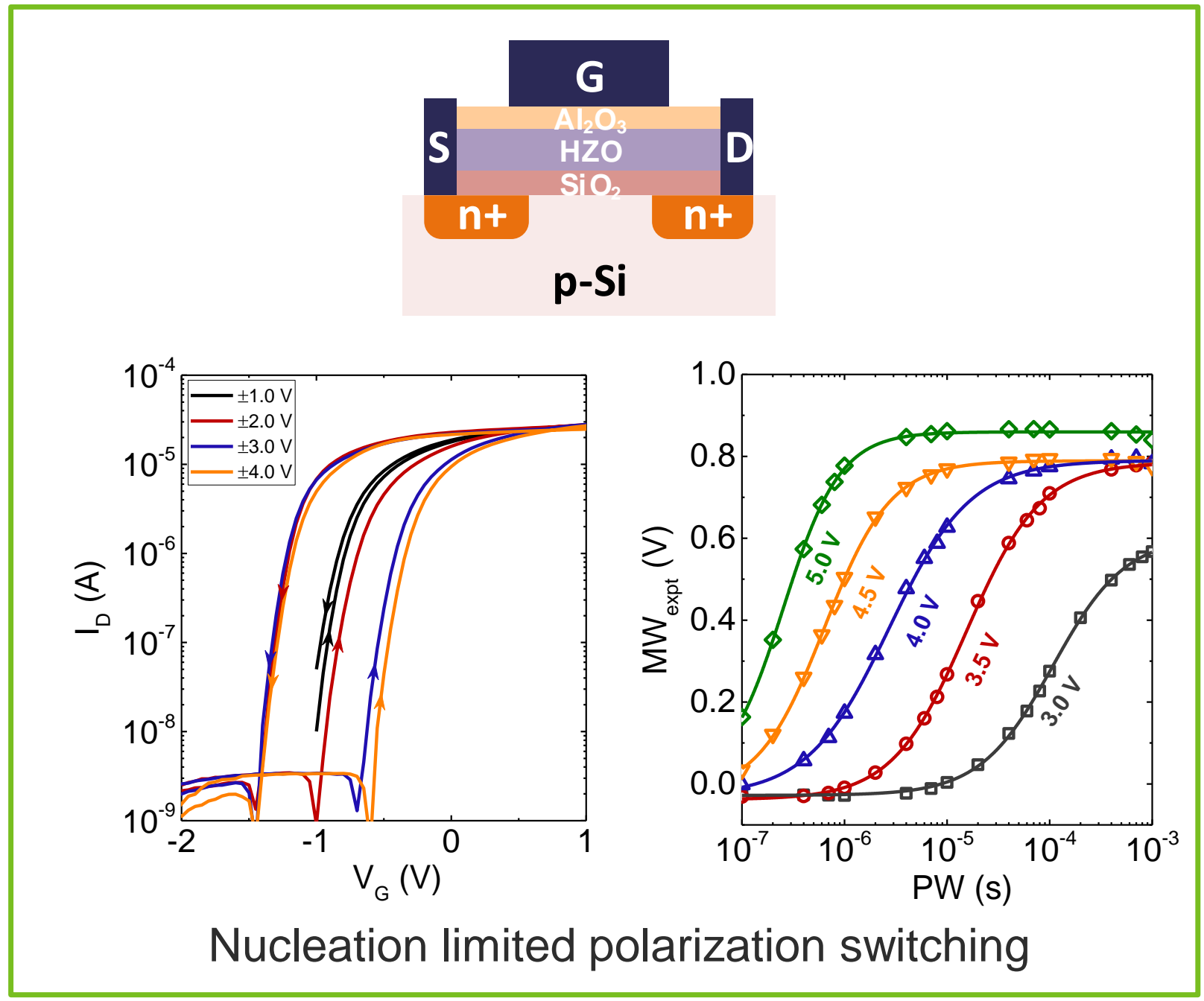

in preparation $\mathrm{Ni}$ and Datta

T드. 15 


\section{Variation}

- Excellent variation property for different pulse widths and amplitudes
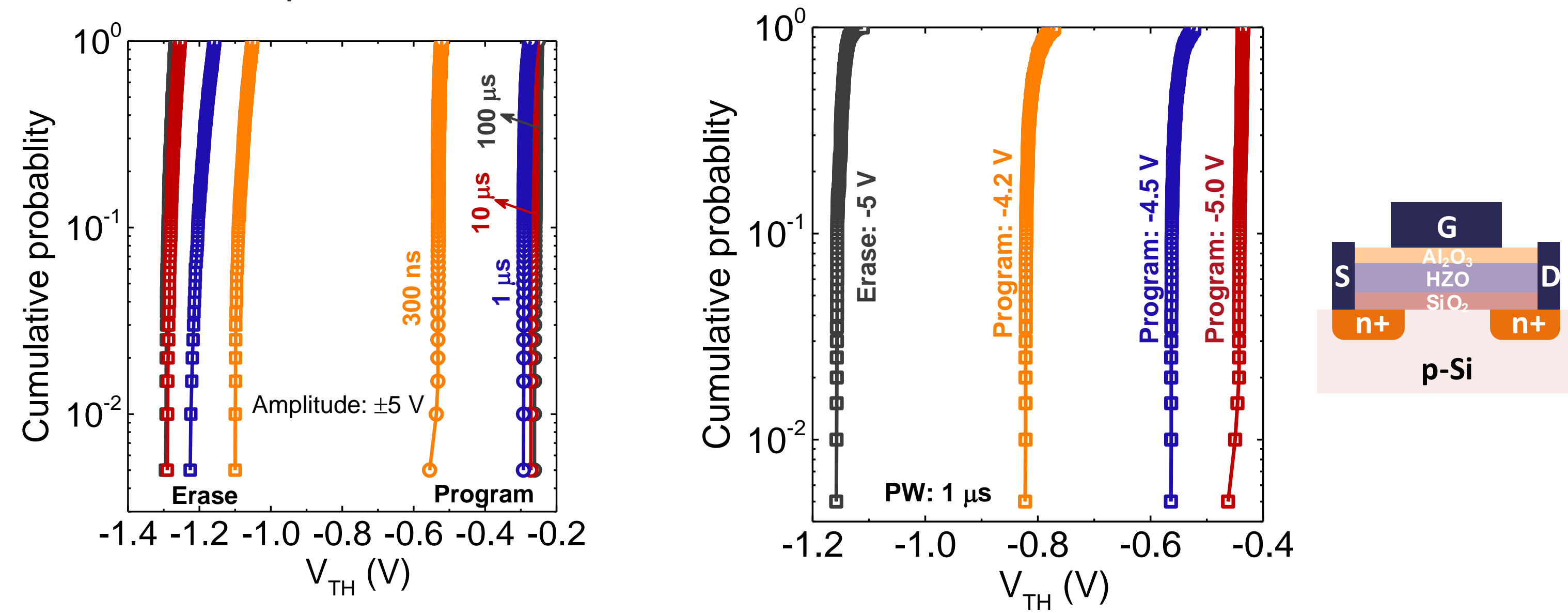


\section{Negative Capacitance FET (theory)}
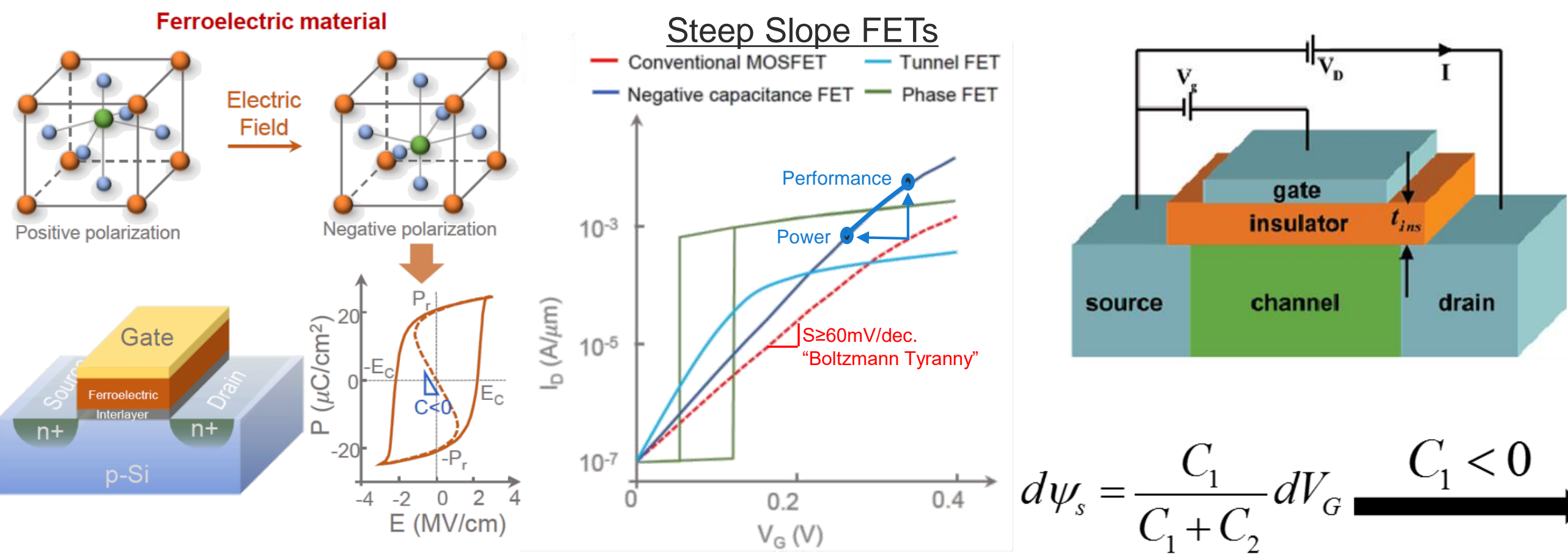

$$
\frac{1}{c_{T}}=\underbrace{\frac{1}{c_{1}}}_{\longrightarrow \text { Negative? }}+\frac{1}{c_{2}}+\frac{1}{c_{3}} \ldots
$$

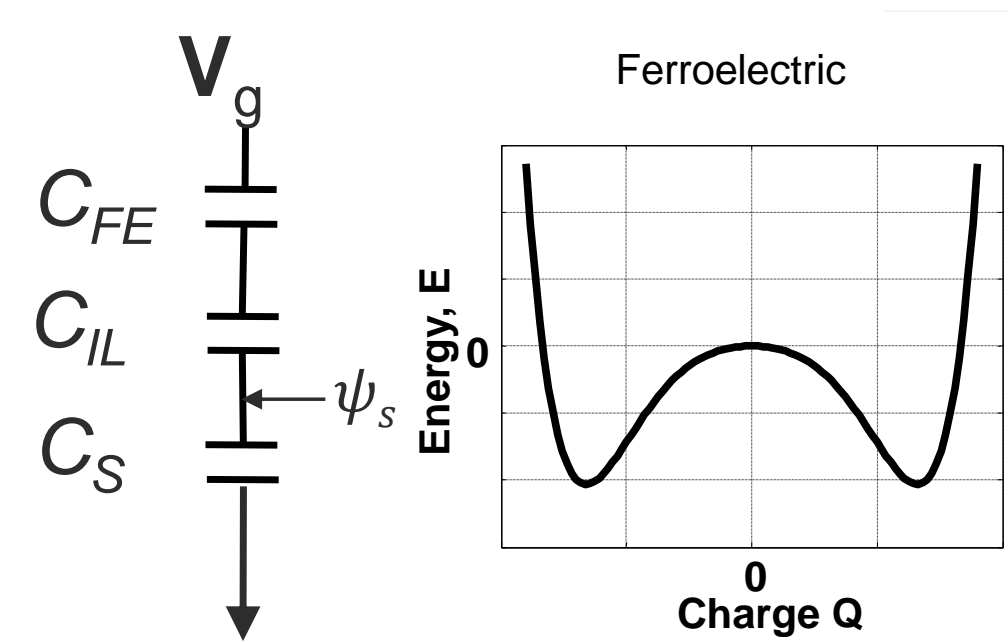

R. Clark / TTCA TFPT / ECS/Aimes 2018 October 1, 2018
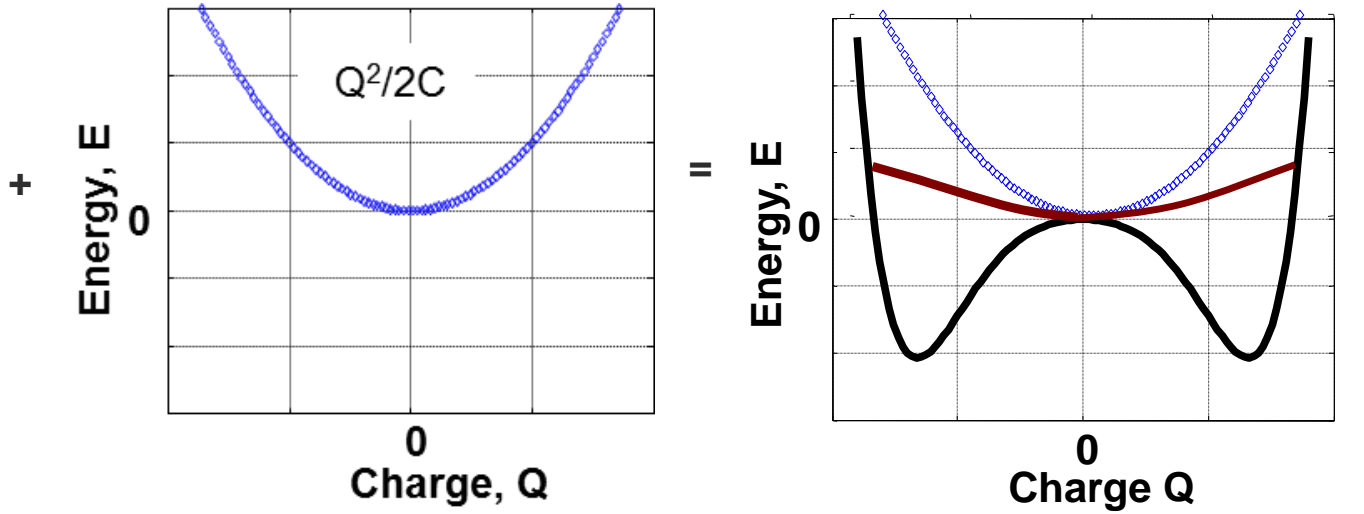

$d \psi_{s}=\frac{C_{1}}{C_{1}+C_{2}} d V_{G} \stackrel{C_{1}<0}{\longrightarrow} d \psi_{s}=\frac{\left|C_{1}\right|}{\left|C_{1}\right|-C_{2}} d V_{G}$
- A gain $\frac{\mathrm{d} \psi_{s}}{d V_{g}}>1$ is possible

- The amount of gain is dependent upon how well $\mathrm{C}_{2}$ is matched to $\left|\mathrm{C}_{1}\right|$

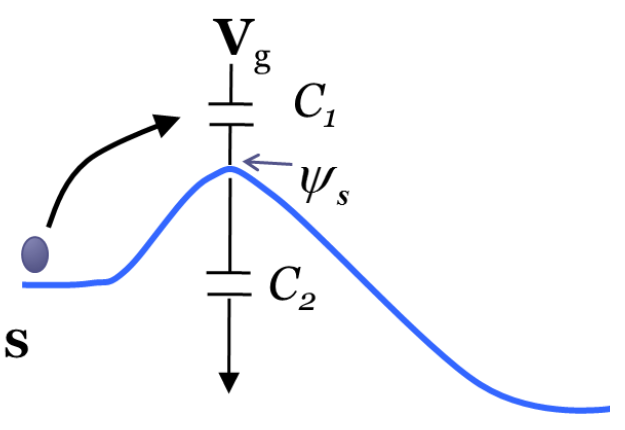

Salahuddin VLSI-TSA 2018

Salahuddin et. al. Nature Electronics, 1, 2018, 442-50.

T드․ 17 


\section{Negative Capacitance FETs using Ferroelectric Hf/ZrO}

Scaled Gate Last Hf/ZrO NCFETs

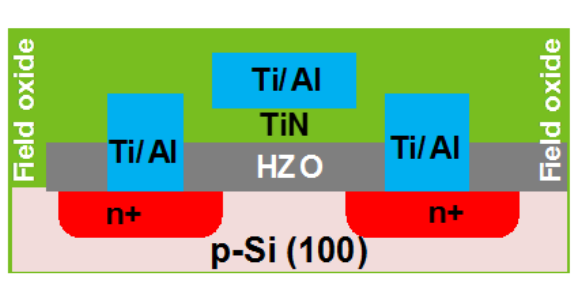

$\mathrm{I}_{\mathrm{DS}}-\mathrm{V}_{\mathrm{GS}}$ Characteristics

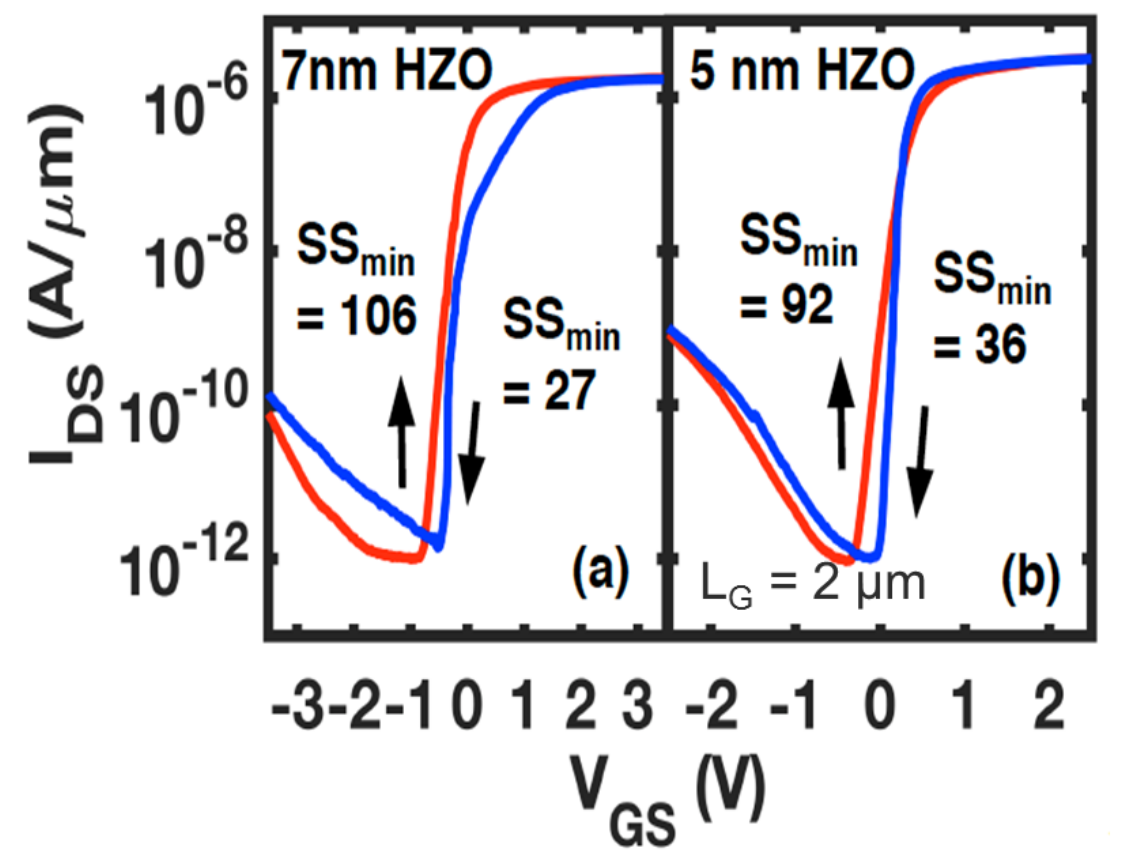

R. Clark / TTCA TFPT / ECS/Aimes 2018 October 1, 2018

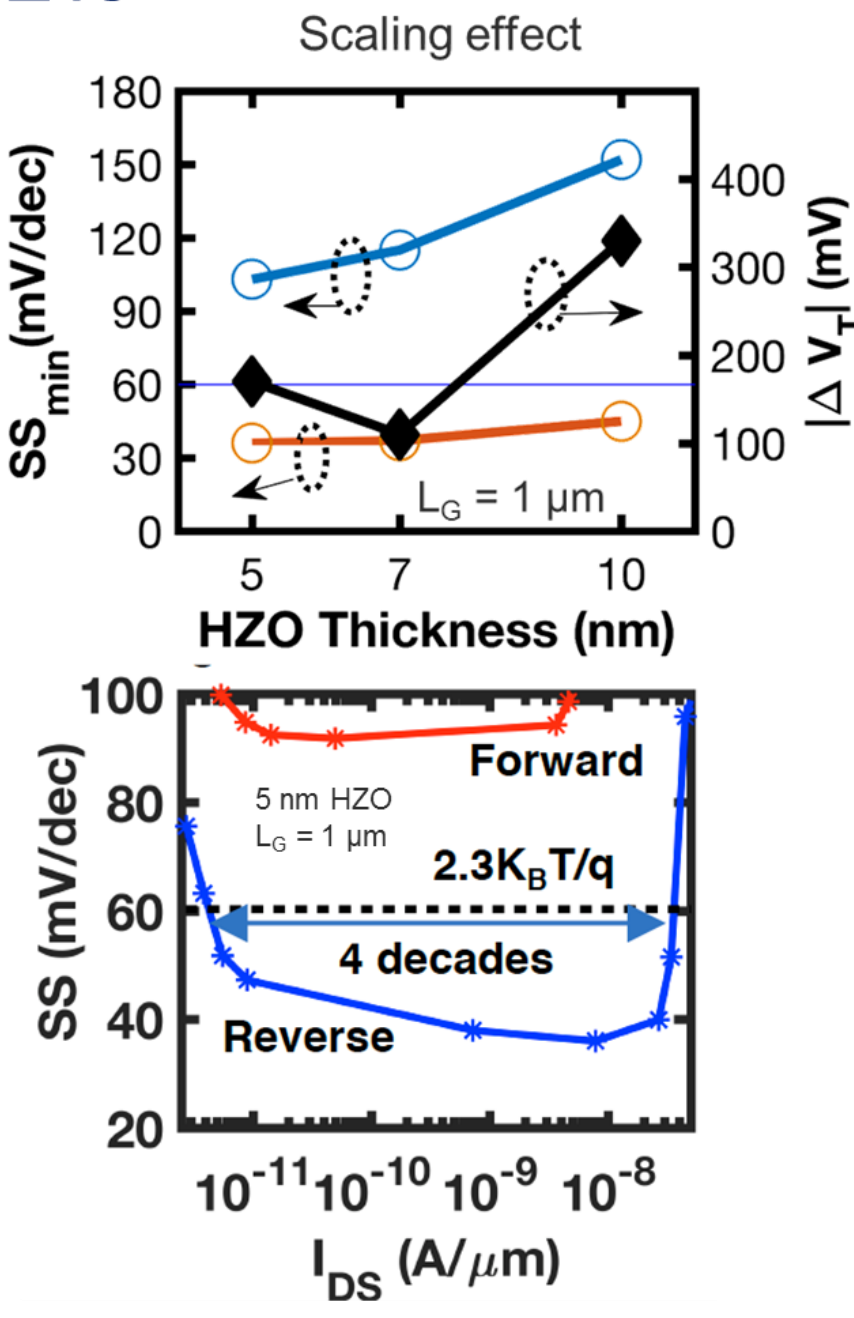

FerroFET

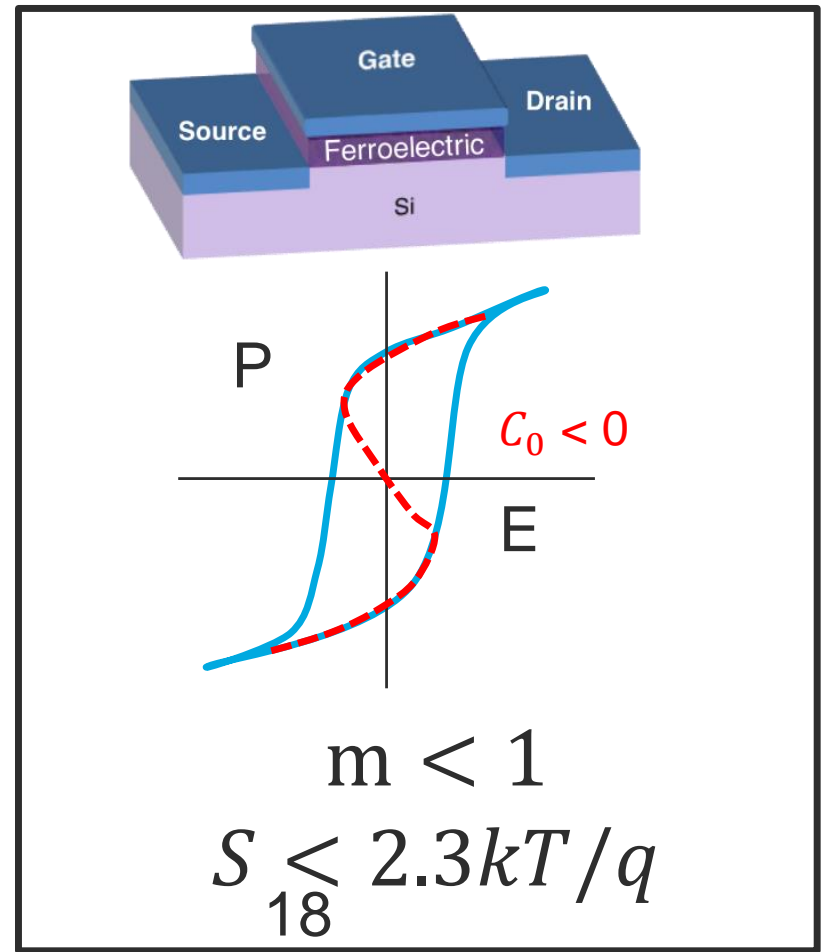

Ferroelectric in a hysteretic NCFET

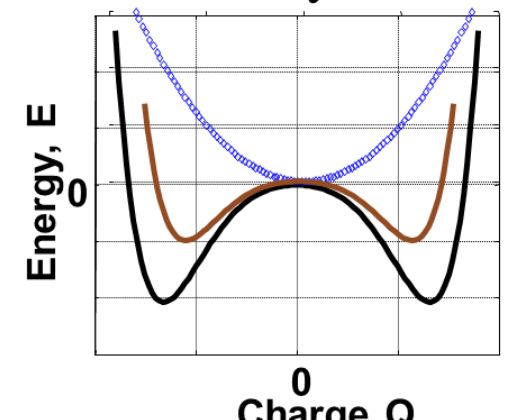

Hysteretic with Trapping

Tㄷㄴ. 18 


\section{Neuromorphic: Ferroelectric Synapse}

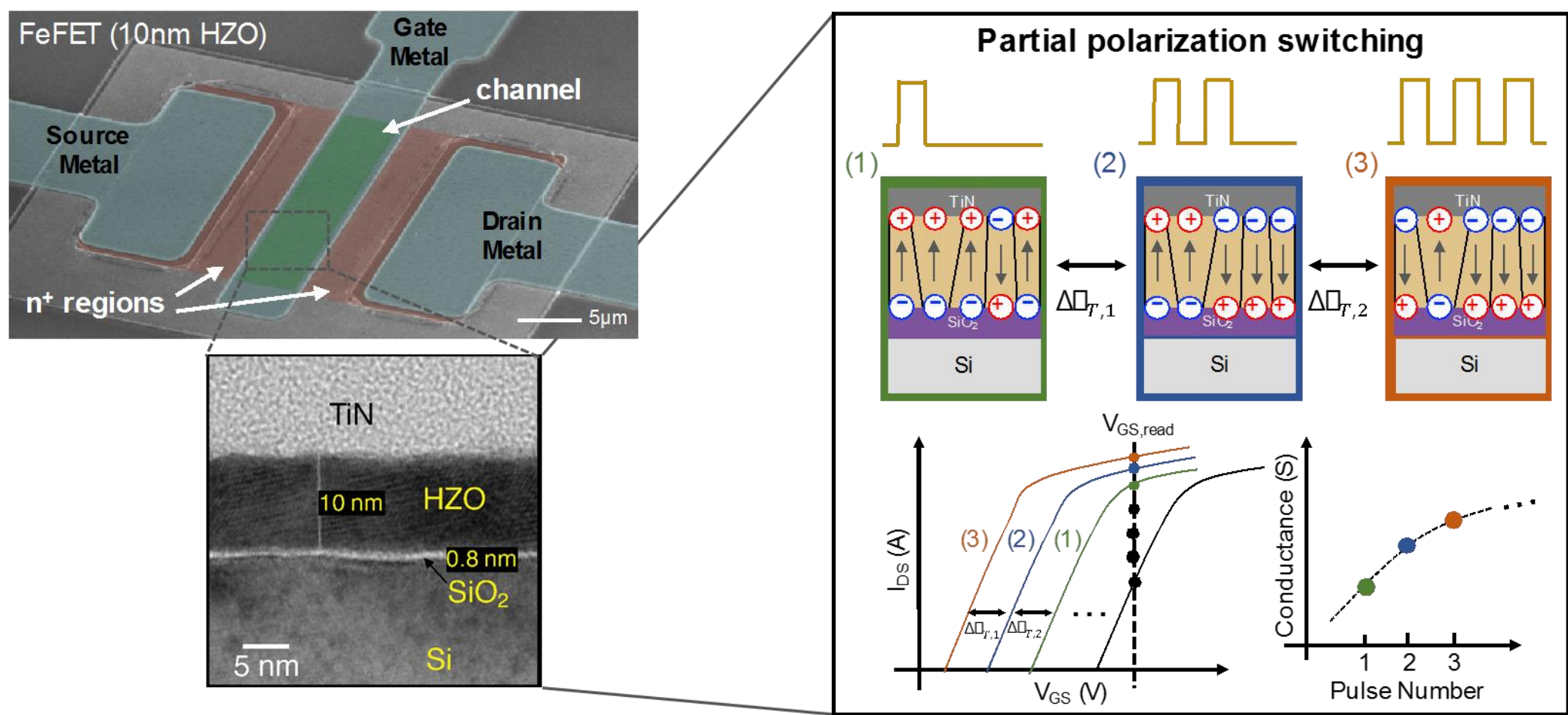

- Electric-field controlled partial polarization switching in ferroelectrics FETs can be harnessed for synaptic memory with nanosecond updates.

FeFETs have potential applications as neuromorphic computing components Bring memory and computing together

R. Clark / TTCA TFPT / ECS/Aimes 2018 October 1, 2018

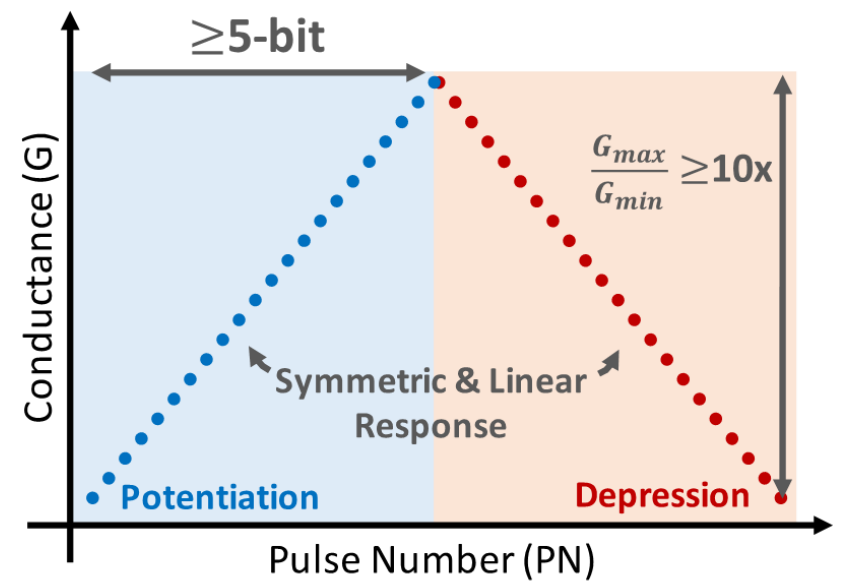

Pulse Scheme 3
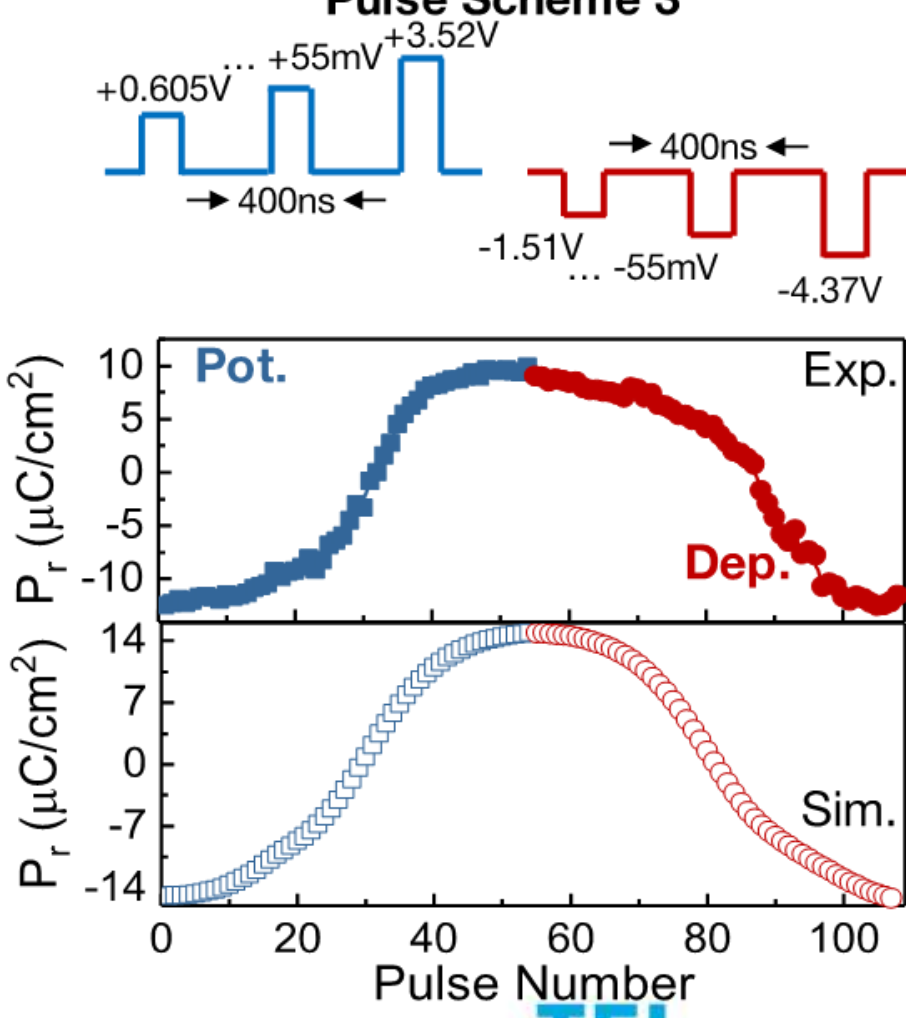

뜬. 19 


\section{Summary}

- Accomplishment

- Ferroelectric HfZrO was demonstrated and investigated for logic and memory applications

- Effects of Thickness, Composition, and MIM vs. MIS Structure have been investigated

- Polarization is enhanced by using cap technique

- Cap material dependence of memory windows are evaluated

- High-k interlayer is better than $\mathrm{SiO}_{2}$ interlayer both in memory window and breakdown voltage

- Steep SS $<60 \mathrm{mV} /$ dec. realized during ferroelectric switching (NCFET)

- Stable and Uniform switching characteristics can enable nonvolatile logic for Neuromorphic applications

- Future plan

- Realizing Ferro-electric phase with $<5 \mathrm{~nm}$ thickness

- Understanding how structural effects impact electrical behavior and breakdown

- Expanding memory window 


\section{Acknowledgements}

- Tokyo Electron Staff- especially the operations, service, engineering and development staff at TEL Technology Center, America (TTCA)

- The past and present group members of professors Alain Diebold and Nate Cady at SUNY Polytechnic Institute, and professor Suman Datta at Notre Dame. Especially Sonal Dey and Pankaj Sharma

- Professor Sayeef Salahuddin for helpful discussions 


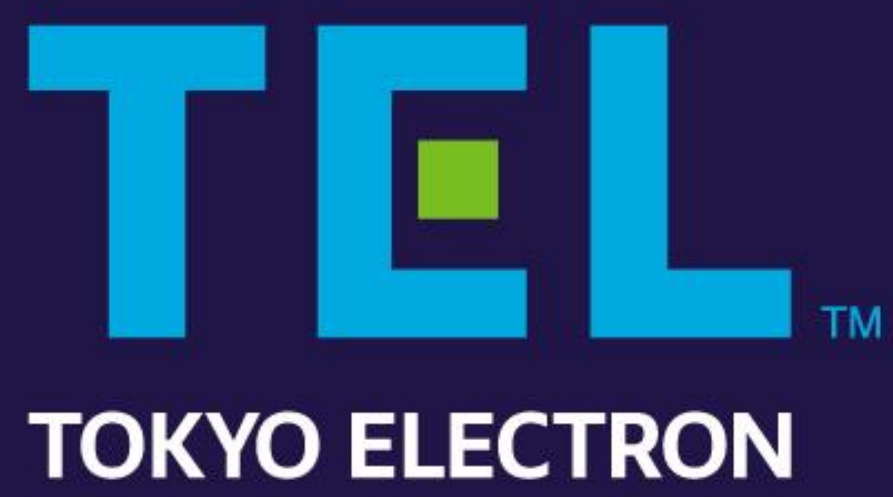

